Published in final edited form as:

Sci Signal. ; 7(333): ra66. doi:10.1126/scisignal.2005052.

\title{
AKAP150-dependent cooperative TRPV4 channel gating is central to endothelium-dependent vasodilation and is disrupted in hypertension
}

\author{
Swapnil K. Sonkusare ${ }^{1}$, Thomas Dalsgaard ${ }^{1}$, Adrian D. Bonev ${ }^{1}$, David C. Hill-Eubanks ${ }^{1}$, \\ Michael I. Kotlikoff ${ }^{2}$, John D. Scott ${ }^{3}$, Luis F. Santana ${ }^{4}$, and Mark T. Nelson ${ }^{1,5,{ }^{*}}$ \\ ${ }^{1}$ Department of Pharmacology, College of Medicine, University of Vermont, Burlington, VT 05403, \\ USA. \\ 2Department of Biomedical Sciences, College of Veterinary Medicine, Cornell University, Ithaca, \\ NY 14853, USA. \\ ${ }^{3}$ Howard Hughes Medical Institute and Department of Pharmacology, University of Washington, \\ Seattle, WA 98195, USA. \\ ${ }^{4}$ Department of Physiology and Biophysics, University of Washington, Seattle, WA 98195, USA. \\ 5Institute of Cardiovascular Sciences, University of Manchester, Manchester M13 9NT, UK.
}

\section{Abstract}

Copyright 2008 by the American Association for the Advancement of Science; all rights reserved.

Permissions Obtain information about reproducing this article: http://www.sciencemag.org/about/permissions.dtl

*Corresponding author. mark.nelson@uvm.edu.

\section{SUPPLEMENTARY MATERIALS}

www.sciencesignaling.org/cgi/content/full/7/333/ra66/DC1

Fig. S1. Relationship between GSK101 concentration and TRPV4-mediated whole-cell $\mathrm{K}^{+}$currents.

Fig. S2. TRPV $4 \mathrm{Ca}^{2+}$ sparklets at MEPs recorded in the presence of GSK101 and CPA.

Fig. S3. CCh activates TRPV4 sparklets at MEPs through the PLC-DAG-PKC pathway in the presence of CPA and GSK101.

Fig. S4. Bradykinin activates TRPV4 sparklets at MEPs in a PKC-dependent manner.

Fig. S5. PKCa is not preferentially localized at MEPs.

Fig. S6. Sparklet sites have a maximum of four TRPV4 channels.

Fig. S7. Ratio of the experimentally observed $P_{\mathrm{O}}$ of TRPV4 channels to the $P_{\mathrm{O}}$ predicted by the binomial distribution assuming independent gating of TRPV4 channels.

Fig. S8. Inhibition or activation of the GqPCR-PKC-TRPV4 pathway does not alter the functional coupling of TRPV4 channels.

Fig. S9. Inhibition of PKC or IK channels attenuates dilation to CCh.

Fig. S10. The EDH component of CCh-induced vasodilation is abolished in Ang II-induced hypertension.

Fig. S11. CCh-induced increases in whole-cell $\mathrm{Ca}^{2+}$ in ECs and IK channel localization at MEPs are unaltered in hypertension.

Table S1. Number and density of IK, SK, and TRPV4 channels in ECs.

Table S2. Internal diameters of CCh-dilated third-order mesenteric arteries from NT and hypertensive mice.

Table S3. Internal diameters of GSK101-dilated third-order mesenteric arteries from NT and hypertensive mice.

Table S4. General properties of mesenteric arteries and ECs from NT and hypertensive (HT) mice.

Movie S1. Z-stack of AKAP150 staining images across the $z$ axis from the luminal surface to the SMC layer in NT mice.

Movie S2. Z-stack of AKAP150 staining images across the $z$ axis from the luminal surface to the SMC layer in hypertensive mice.

Author contributions: S.K.S., L.F.S., and M.T.N. designed the research; S.K.S., T.D., and A.D.B. performed the experiments and analyzed the data; S.K.S., T.D., A.D.B., D.C.H.-E., and M.T.N. interpreted the data; S.K.S., D.C.H.-E., and M.T.N. wrote and edited the paper; L.F.S. provided the software and expertise for coupling coefficient analysis; J.D.S. provided AKAP150 ${ }^{-/}$mice; M.I.K. contributed to the studies with GCaMP2 mice; and all the authors contributed to manuscript revisions.

Competing interests: The authors declare that they have no competing interests.

Data and materials availability: The GCaMP2 $\mathrm{Cx} 40$ mice are available through the Cornell Center for Technology Enterprise and Commercialization (CCTEC). Contact mta-cctec@cornell.edu for a material transfer agreement. 
Endothelial cell dysfunction, characterized by a diminished response to endothelial cell-dependent vasodilators, is a hallmark of hypertension. TRPV4 channels play a major role in endothelialdependent vaso-dilation, a function mediated by local $\mathrm{Ca}^{2+}$ influx through clusters of functionally coupled TRPV4 channels rather than by a global increase in endothelial cell $\mathrm{Ca}^{2+}$. We showed that stimulation of muscarinic acetylcholine receptors on endothelial cells of mouse arteries exclusively activated TRPV4 channels that were localized at myoendothelial projections (MEPs), specialized regions of endothelial cells that contact smooth muscle cells. Muscarinic receptormediated activation of TRPV4 depended on protein kinase C (PKC) and the PKC-anchoring protein AKAP150, which was concentrated at MEPs. Cooperative opening of clustered TRPV4 channels specifically amplified $\mathrm{Ca}^{2+}$ influx at MEPs. Cooperativity of TRPV4 channels at nonMEP sites was much lower, and cooperativity at MEPs was greatly reduced by chelation of intracellular $\mathrm{Ca}^{2+}$ or AKAP150 knockout, suggesting that $\mathrm{Ca}^{2+}$ entering through adjacent channels underlies the AKAP150-dependent potentiation of TRPV4 activity. In a mouse model of angiotensin II-induced hypertension, MEP localization of AKAP150 was disrupted, muscarinic receptor stimulation did not activate TRPV4 channels, cooperativity among TRPV4 channels at MEPs was weaker, and vasodilation in response to muscarinic receptor stimulation was reduced. Thus, endothelial-dependent dilation of resistance arteries is enabled by MEP-localized AKAP150, which ensures the proximity of PKC to TRPV4 channels and the coupled channel gating necessary for efficient communication from endothelial to smooth muscle cells in arteries. Disruption of this molecular assembly may contribute to altered blood flow in hypertension.

\section{INTRODUCTION}

The endothelium lining blood vessels exerts an important vasodilatory influence over adjacent smooth muscle, and is thus a pivotal regulator of vascular tone and blood flow. This vasodilatory function is often disrupted in vascular disorders such as hypertension. Endothelium-dependent vasodilation in response to classically used experimental agents, such as acetylcholine (ACh) (1), depends on an increase in endothelial cell (EC) calcium $\left(\mathrm{Ca}^{2+}\right)$. In addition to mobilization of $\mathrm{Ca}^{2+}$ from intracellular stores (2-6), influx of extracellular $\mathrm{Ca}^{2+}$ is a major contributor to $\mathrm{EC} \mathrm{Ca}^{2+}$ signals (6-14). Increased intracellular $\mathrm{Ca}^{2+}$ concentrations activate $\mathrm{Ca}^{2+}$-sensitive molecular targets, including endothelial nitric oxide synthase (eNOS) (15), phospholipase $\mathrm{A}_{2}$ (16), and small- and intermediateconductance $\mathrm{Ca}^{2+}$-sensitive potassium (SK and IK) channels $(17,18)$. Whereas activation of the first two pathways promotes vasodilation through the production of soluble vasodilators —nitric oxide (NO) and cyclooxygenase (COX) products, respectively—engagement of the third channel-mediated mechanism leads to endothelium-dependent hyperpolarization (EDH), which spreads through gap junctions in specialized EC projections to adjacent smooth muscle cells (SMCs) called myoendothelial projections (MEPs), causing dilation of small resistance arteries and arterioles by decreasing the activity of voltage-dependent $\mathrm{Ca}^{2+}$ channels (VDCCs) in SMCs (2, 5). Many of the molecular players involved in EDHmediated vasodilation have been identified; however, their signaling linkages and the spatial organization of signaling complexes remain poorly understood.

Members of the transient receptor potential (TRP) family of nonselective cation channels, particularly the vanilloid subfamily member TRPV4, represent important $\mathrm{Ca}^{2+}$ influx 
pathways in ECs $(6,8-12,19)$. Previously, we reported the optical detection of $\mathrm{Ca}^{2+}$ influx through single TRPV4 channels ("sparklets") in ECs of intact, small mesenteric arteries from mice, and showed that TRPV4 sparklets activated IK channels to induce vasodilation (6). These elementary TRPV4-mediated events exhibited cooperative gating among channels in a four-channel metastructure and were non-randomly distributed across the EC membrane, occurring more frequently at "holes" in the internal elastic lamina corresponding to gaps between ECs and SMCs, identified by their lack of autofluorescence (4,19-22). Located at these gaps are MEPs, specialized projections through the internal elastic lamina demarking EC microdomains that connect ECs with adjacent SMCs. These microdomains contain localized clusters of ion channels, including TRPV4 and IK channels (4, 19-22).

The TRPV4-IK module is a downstream target of the muscarinic ACh receptor signaling pathway (6). A majority of the EDH component of muscarinic agonist-induced dilation of isolated small mesenteric mouse arteries depends on activation of EC TRPV4 channels (6). Consistent with this, ACh-induced SMC hyperpolarization and dilation of mesenteric arteries are seriously impaired in TRPV $4^{-/-}$mice $(7,12)$. Studies in heterologous expression systems and cultured ECs suggest a role for protein kinase C (PKC) in the pathway linking muscarinic receptors to activation of TRPV4 channels (23). It has also been shown that the kinase- and phosphatase-anchoring protein AKAP150 (A-kinase anchoring protein 150; AKAP79 in humans) is involved in the activation of TRPV4 channels by PKC (24).

Endothelial function, which is essential for controlling blood flow and vascular resistance, is impaired in hypertension. A common feature of endothelial dysfunction observed in animal models of hypertension, as well as in humans, is compromised endothelial-dependent vasodilation to muscarinic receptor agonists (25-31). Proposed mechanisms to account for this loss of endothelium-dependent vasodilation typically invoke decreased expression of genes encoding specific signaling pathway components or mechanisms that otherwise control the abundance of these components $(26,31,32)$.

In our recent study, we found that as few as three active TRPV4 channels per EC can maximally dilate mesenteric arteries (6), demonstrating the operation of a highly efficient TRPV4-IK signaling module that can leverage a modest initial stimulus into a profound physiological response. However, these observations pose a dilemma: How can channels present at low density couple with such high efficiency? The combined amplifier effect of cooperative TRPV4 channel gating and the high $\mathrm{Ca}^{2+}$ sensitivity of IK channels highlighted in our previous report offers a partial answer, but it cannot fully account for these almost single molecule level events. Here, we investigated the signaling network that enables effective endothelial-dependent dilation in resistance-sized arteries and explored the pathological mechanisms underlying its impairment in hypertension. Our findings may resolve the dilemma posed above, providing support for a model in which clustering of EDH-dependent signaling elements in the PKC/AKAP150-TRPV4-IK signaling pathway at MEPs facilitates efficient communication among these elements. An important feature of this model is AKAP150 localization of PKC at MEPs, which enables muscarinic receptor signaling to activate TRPV4 channels exclusively at these microdomains. We also found that AKAP150 localization at MEPs was disrupted in a mouse model of hypertension, 
resulting in defective signaling between muscarinic receptors and TRPV4 channels and among TRPV4 channels at MEPs, and leading to impaired endothelial-dependent dilation.

\section{RESULTS}

\section{Muscarinic receptor stimulation activates TRPV4 channels exclusively at MEPs}

The low density of TRPV4 channels and IK channels in the EC membrane (table S1) raises fundamental questions about how these sparse ion channels maintain the functional linkages necessary for efficient signaling to SMCs. To elucidate the muscarinic receptor-TRPV4 signaling network and its organization, we assessed the spatial distribution of TRPV4 sparklets in ECs of native, resistance-size, mouse mesenteric arteries after stimulation with the muscarinic agonist carbachol $(\mathrm{CCh})$. These experiments used an en face preparation (see Materials and Methods) of mesenteric arteries from mice expressing the genetically encoded $\mathrm{Ca}^{2+}$ indicator GCaMP2 exclusively in the vascular endothelium, an approach that allows EC signals to be detected simultaneously in $\sim 14 \mathrm{ECs}$ without interference from $\mathrm{SMC} \mathrm{Ca}^{2+}$ signaling (4, 6, 33-35). TRPV4 sparklets were measured in the presence of the sarcoplasmic reticulum and endoplasmic reticulum (SR/ER) $\mathrm{Ca}^{2+}-$ ATPase (adenosine triphosphatase) inhibitor cyclopiazonic acid (CPA) (6), which blocks SR and ER $\mathrm{Ca}^{2+}$ uptake, thereby depleting these compartments of $\mathrm{Ca}^{2+}$ and eliminating $\mathrm{IP}_{3}$ (inositol 1,4,5-trisphosphate) receptor $\left(\mathrm{IP}_{3} \mathrm{R}\right)$-mediated $\mathrm{Ca}^{2+}$ signals. Under this basal (unstimulated) condition, TRPV4 sparklets were infrequent ( 4 events per 2-min recording per field), and most $(\sim 89 \%)$ of the sparklet sites were at MEPs. Muscarinic receptor stimulation with CCh $(10 \mu \mathrm{M})$ induced a significant increase in TRPV4 sparklet activity per field, expressed as fluorescence integral (see Materials and Methods for details). This increase in activity occurred exclusively at MEP sites, defined as sites within $5 \mu \mathrm{m}$ of the center of a hole in the internal elastic lamina (Fig. 1, A to C). Over the recording period, $\mathrm{CCh}$ increased the number of active sites per field, as well as the average number of active channels $\left(N P_{\mathrm{O}}\right)$ per site (Table 1) (see Materials and Methods). The TRPV4 antagonist HC-067047 inhibited the CCh-induced increase in sparklet activity (Fig. 1C), confirming that these events are TRPV4-mediated.

To evaluate TRPV4 channel activity at non-MEP sites and to increase the overall frequency of events and thereby facilitate statistical analyses, we evaluated sparklet activity induced by $\mathrm{CCh}$ in the presence of a submaximal concentration $(3 \mathrm{nM})$ of the specific TRPV4 agonist GSK1016790A (hereinafter GSK101) (fig. S1). This concentration of GSK101 increased TRPV4 sparklet activity at both MEP (illustrated in fig. S2) and non-MEP sites. Consistent with results obtained in the absence of GSK101 (Fig. 1, A to C), all newly occurring events after the addition of CCh were localized to MEP sites (Fig. 1, D and E, and fig. S3A), where sparklet activity, the number of sites exhibiting sparklets, and the $N P_{\mathrm{O}}$ per site were significantly increased (Table 1). Collectively, these results indicate that muscarinic receptor stimulation selectively activates TRPV4 channels at MEPs.

\section{Muscarinic receptor stimulation activates MEP-associated TRPV4 channels through PKC}

Muscarinic receptors [the M3 subtype in ECs (5)], and other G protein (heterotrimeric guanine nucleotide-binding protein)-coupled receptors (GPCRs) that signal through $\mathrm{Ga}_{\mathrm{q}}$, stimulate phospholipase $\mathrm{C}$ (PLC) to produce $\mathrm{IP}_{3}$ and diacylglycerol (DAG), which in turn 
activate $\mathrm{IP}_{3} \mathrm{Rs}$ and PKC, respectively. To determine whether CCh stimulation of TRPV4 sparklets occurred through the GPCR-Ga $\mathrm{q}_{\mathrm{q}}$-PLC-DAG-PKC pathway in ECs, we tested the effects of pharmacological inhibition of PLC and activation of PKC. Pretreatment with the PLC inhibitor U73122 prevented activation of sparklets by CCh in the absence of GSK101 (Table 1), consistent with the involvement of PLC in the signaling pathway. Direct activation of PKC with the DAG analog, 1-oleoyl-2-acetyl-sn-glycerol (OAG), or the PKC activator phorbol myristate acetate (PMA) induced TRPV4 sparklet activity at MEPs to an extent similar to that induced by $\mathrm{CCh}$ (Fig. 1C). Both OAG and PMA increased the number of active sites per field and $N P_{\mathrm{O}}$ per site (Table 1). The number of sparklet sites and $N P_{\mathrm{O}}$ per site were not changed by CCh, OAG, or PMA in the presence of the selective PKC inhibitor Gö-6976 (Fig. 1C and Table 1). The TRPV4 antagonist HC-067047 prevented the increase in sparklet activity that occurred in response to CCh, OAG, or PMA (Fig. 1C and Table 1). Similar results were obtained in the presence of GSK101 (Fig. 1E, Table 1, and fig. S3, A to C). Both OAG and PMA induced sparklet activity only at the MEP sites and were without effect on sparklets at non-MEP sites (Fig. 1E and fig. S3, B and C). Bradykinin, an agonist of another $\mathrm{G}_{\mathrm{q}}$-coupled GPCR, also induced TRPV4 sparklets exclusively at MEPs in a PKC-dependent manner (fig. S4). Collectively, these results indicate that $\mathrm{G}_{\mathrm{q}}$-coupled GPCR signaling to MEP-localized TRPV4 channels is mediated by the PLC-DAG-PKC pathway.

\section{AKAP150 anchors PKC at MEPs to mediate activation of TRPV4 sparklets by muscarinic receptors}

The fact that $\mathrm{G}_{\mathrm{q}}$-coupled GPCR activation of TRPV4 sparklets was PKC-dependent and occurred specifically at MEPs suggests the presence of a channel-associated or MEPlocalized pool of PKC. The association of kinases with channels is often mediated by scaffolding proteins of the AKAP family (36), and AKAP150, which has been implicated in PKC activation of TRPV4 channels (24) and VDCCs in SMCs $(37,38)$, is a likely candidate.

Immunofluorescence imaging of fixed tissue showed that AKAP150 was concentrated in the region around MEPs (Fig. 2A), whereas PKCa was widely distributed in ECs, including at MEPs (fig. S5). AKAP150 immunofluorescence was observed at 93\% of the holes in the internal elastic lamina, defined as peak staining within $5 \mu \mathrm{m}$ of the center of a hole. A series of z-stack confocal images captured through the internal elastic lamina from the bottom surface of the EC to the top surface of the SMC revealed the presence of AKAP150 at all planes in the internal elastic lamina (Fig. 2B), with the strongest AKAP150 staining observed toward the ends of projections nearest to the SMCs (movie S1 and Fig. 2B).Most AKAP150 immunofluorescence was centered on holes (Fig. 2, A and B), with a spatial spread (maximum width from half-maximum amplitude) of $14.5 \pm 0.6 \mu \mathrm{m}^{2}(n=104 \mathrm{MEPs})$.

To test the role of AKAP150 in anchoring PKC close to TRPV4 channels, we examined the effects of muscarinic receptor stimulation on endothelial TRPV4 sparklet activity in Fluo-4loaded mesenteric arteries from AKAP150-/- mice (39), which do not express GCaMP2. In the presence of GSK101 (to increase basal activity), CCh increased sparklet activity at MEPs in Fluo-4-loaded mesenteric arteries from wild-type mice, but had no effect on 
sparklet activity in arteries from AKAP150 ${ }^{-/-}$mice (Fig. 2, C and D). Thus, AKAP150 is required for muscarinic receptor-mediated, PKC-dependent activation of TRPV4 channels at MEPs.

\section{Stronger cooperativity of TRPV4 channel openings at MEPs causes enhanced local $\mathrm{Ca}^{2+}$ influx}

TRPV4 channels within a sparklet site function cooperatively, most likely as a four-channel metastructure (6). In the presence of GSK101, TRPV4 channel activity was increased throughout the cell membrane (Fig. 3A left), an effect that was significantly greater at MEP sites than at sites elsewhere in the cell (Fig. 3A, right). The maximum number of quantal levels-stepwise increases in fluorescence, with each level corresponding to a multiple of the fluorescence associated with the opening of a single channel-was four at both MEP and non-MEP sites (fig. S6, A and B). Because the basic architecture of TRPV4 channel complexes appeared similar at MEP and non-MEP sites, we hypothesized that the increased TRPV4 channel activity at MEPs resulted from enhanced cooperative gating (also called functional coupling). We applied a coupled Markov chain model (40) to determine the coupling coefficient ( $\kappa)$ among TRPV4 channels within $\mathrm{Ca}^{2+}$ sparklet sites, an approach that we have used previously to examine the strength of coupling among VDCCs $(37,41)$. The $\mathrm{K}$ value can range from 0 for channels that open independently to 1 for "tightly" coupled channels that open and close simultaneously (see Materials and Methods). Using this approach and $\kappa \geq 0.1$ as a threshold value for functional coupling (37), we found that $\sim 86 \%$ of MEP sparklet sites and $28 \%$ of non-MEP sparklet sites in artery preparations from GCaMP2 mice displayed coupled gating of TRPV4 channels. The mean coupling coefficient for TRPV4 sparklets at MEP sites was higher than that for TRPV4 sparklets at non-MEP sites, measured in both GCaMP2 arteries and Fluo-4-loaded wild-type arteries (Fig. 3, B and $\mathrm{C}$ ). A statistical analysis, testing the deviation of the experimentally observed open probability $\left(P_{\mathrm{O}}\right)$ of TRPV4 channels from the binomial distribution expected under an assumption of independent channel gating, confirmed these results, showing that cooperativity significantly increased TRPV4 activity at MEP sites compared to that at nonMEP sites in artery preparations from GCaMP2 mice, as well as Fluo-4-loaded arteries from wild-type mice (fig. S7). We confirmed that TRPV4 sparklets under baseline conditions (that is, in the absence of GSK101) were functionally coupled and that the low concentration (3 nM) of GSK101 used did not affect coupling coefficients at MEP sites (fig. S8). These results indicate that TRPV4 channels exhibit stronger cooperative opening at MEPs and thereby deliver higher $\mathrm{Ca}^{2+}$ into this microdomain.

\section{Cooperative opening of TRPV4 channels depends on AKAP150 and intracellular $\mathrm{Ca}^{2+}$}

TRPV4 channels at MEPs exhibited two distinguishing features: (i) AKAP150 and PKC (AKAP150/PKC)-dependent activation and (ii) increased channel activity associated with channel cooperativity. AKAP150 could act through several possible mechanisms to enhance cooperative channel activity, including allosteric protein-protein interactions and increased TRPV4 phosphorylation by AKAP150-bound PKC. In tests of this latter possibility, we found that although both $\mathrm{CCh}$ and PKC activation with PMA increased sparklet activity at MEPs (Fig. 1, C and E), neither altered the coupling coefficient among TRPV4 channels at MEPs (fig. S8), suggesting that PKC is not responsible for channel cooperativity at MEPs. 
Consistent with this, PKC inhibition with Gö-6976 did not affect the coupling coefficient for GSK101-activated channels (fig. S8).

To determine whether AKAP150 acted independently of PKC to regulate TRPV4 cooperativity, we compared the properties of GSK101-induced TRPV4 sparklets at MEPs in Fluo-4-loaded mesenteric arteries from wild-type and AKAP150-/- mice. After stimulation with GSK101, TRPV4 sparklet activity per site at MEPs from AKAP150 $0^{-/}$mice was less than that at MEPs from wild-type mice (Fig. 3D). The lack of AKAP150 eliminated the difference in sparklet activity between MEP and non-MEP sites (Fig. 3D). A comparison of the coupling strength at MEP and non-MEP sites in both genotypes (Fig. 3, E and F) showed that the $\kappa$ value for TRPV4 channels at MEP sites in AKAP150-/- mice was significantly lower than that at MEP sites in wild-type mice (Fig. 3C). Whereas 95\% of MEP sparklet sites in ECs from wild-type mice showed coupled gating, only $33 \%$ of these sites from AKAP $150^{-/-}$mice were coupled. Overall, TRPV4 sparklet properties at MEP sites in mesenteric ECs from AKAP150-/- mice were similar to those at non-MEP sites (which also lack AKAP150) in ECs from wild-type mice (Fig. 3, A to C). Thus, AKAP150 greatly enhances cooperativity at MEPs, but coupled gating is not completely eliminated in its absence.

Because TRPV4 channels exhibit concentration-dependent potentiation by intracellular $\mathrm{Ca}^{2+}$ $(42,43)$, a local increase in $\mathrm{Ca}^{2+}$ concentration resulting from $\mathrm{Ca}^{2+}$ influx through other TRPV4 channels in a four-channel cluster may contribute to cooperative activity. To test this, we disrupted $\mathrm{Ca}^{2+}$-dependent channel-to-channel communication by chelating intracellular $\mathrm{Ca}^{2+}$ with EGTA-AM. Although EGTA modestly decreased the coupling coefficient of TRPV4 channels at non-MEP sites, it substantially reduced it at MEP sites, essentially eliminating the difference in cooperativity between the two sites (Fig. 3, E and F). Moreover, TRPV4 channel cooperativity-induced increases in $\mathrm{Ca}^{2+}$ influx were lower in AKAP $150^{-/-}$mice and in the presence of EGTA (fig. S7). Thus, cooperative TRPV4 channel gating at MEP sites depends on both AKAP150 and intracellular $\mathrm{Ca}^{2+}$.

\section{MEP localization of PKC and ion channels efficiently links muscarinic receptor signaling to TRPV4-dependent vasodilation}

We previously reported that direct activation of as few as three TRPV4 channels per EC with GSK101 causes maximum vasodilation through activation of IK channels (6). To determine whether this highly efficient vasodilatory signaling mechanism extends to the muscarinic receptor pathway, we measured vasodilation to CCh and TRPV4 sparklet activity in mesenteric arteries constricted with intravascular pressure $(80 \mathrm{mmHg}$; see Materials and Methods) (6). Diameter was measured in the presence of L-NNA (nitro-Larginine; NOS inhibitor) and indomethacin (COX inhibitor) to isolate the EDH-dependent dilation, and with and without the TRPV4 antagonist HC-067047 to determine the TRPV4 component (Fig. 4A). An analysis of TRPV4 sparklet activity and diameter changes showed that the stochastic equivalent of less than one active TRPV4 channel per cell was sufficient to produce $\sim 50 \%$ dilation to $\mathrm{CCh}$ (Fig. $4 \mathrm{~B}$ ). CCh-induced dilation was attenuated by inhibition of PKC with Gö-6976, whereas vasodilation induced by direct activation of TRPV4 channels (with GSK101) or IK channels (with NS309) was unaffected by Gö-6976 
(fig. S9, A and B). Dilation to CCh was almost completely blocked in the presence of the IK channel inhibitor charybdotoxin (fig. S9, A and B). Collectively, these results indicate that muscarinic receptor-mediated stimulation of MEP-localized TRPV4 channels efficiently transduces a dilatory signal through a PKC- and IK-dependent pathway.

\section{Local signaling in MEPs is disrupted in angiotensin II-induced hypertension}

Endothelial dysfunction, which is often measured as reduced vasodilation in response to muscarinic agonists in both animal models and in humans $(25,26,28,30,31)$, contributes to multiple diseases with a vascular component $(25,29,44-48)$. To explore the mechanisms that lead to endothelial dysfunction in hypertension, we examined endothelial function in a mouse model of angiotensin II (Ang II)-induced hypertension (49). After 3 weeks of continuously infusing mice with Ang II (1.4 mg/kg per day), systolic blood pressures were $184.0 \pm 3.7 \mathrm{mmHg}$ in Ang II hypertensive mice compared with $119.2 \pm 1.9 \mathrm{mmHg}$ before the start of infusion $(n=31$ mice $)$.

To determine the endothelium-dependent dilatory responses of mesenteric arteries from hypertensive and normotensive mice, we measured diameters of pressurized, isolated arteries after exposure to $\mathrm{CCh}$. Application of intravascular pressure $(80 \mathrm{mmHg})$ constricted arteries from both hypertensive and normotensive mice by about $25 \%$, indicating that myogenic mechanisms are unchanged in this model of hypertension. Endothelial-dependent dilation of pressurized arteries in response to $\mathrm{CCh}$ was significantly reduced in arteries from the hypertensive mice (Fig. 5, A and B, fig. S10A, and table S2), in agreement with a previous report (26). The remaining dilation was eliminated by inhibiting NOS with L-NNA (fig. S10, B and C), suggesting that the NO component, which normally constitutes 20 to $30 \%$ of the dilatory response to muscarinic receptor stimulation in these arteries (6), is largely unchanged in this model of hypertension. These results indicate that the predominant defect in Ang II- induced hypertensive mice is an almost complete loss of the EDH component of CCh-induced, endothelial-dependent dilation.

Consistent with loss of the EDH component of vasodilation, dilation to low-level activation of TRPV4 channels (3 nM GSK101) was also significantly attenuated in arteries from hypertensive mice (Fig. 5, A and B, and table S3). A higher concentration of GSK101 (10 $\mathrm{nM}$ ) completely dilated the arteries, possibly suggesting that the density of TRPV4 channels was decreased in hypertensive mice. To test this, we measured maximum current density, an indication of channel numbers, in freshly isolated ECs (see Materials and Methods). The current densities of TRPV4 channels, as well as those of IK and SK channels (the downstream targets of TRPV4 in the EDH pathway), were similar between normotensive and hypertensive animals (Fig. 5C). These results indicate that the functions of ion channels responsible for mediating the EDH component of CCh-induced dilation remained intact, suggesting that communication among these elements in MEPs or between MEPs and smooth muscle was impaired in hypertensive mice. Exposure to NS309, a synthetic, direct activator of IK and SK channels, produced maximal dilation in arteries from hypertensive mice (Fig. 5, D and E, and table S4), ruling out impaired communication between MEPs and smooth muscle. Collectively, these data indicate that the defect in CCh-induced vasodilation in this hypertension model is upstream of IK and SK channels. Moreover, CCh-induced 
increases in whole-cell $\mathrm{Ca}^{2+}$, primarily mediated by $\mathrm{IP}_{3} \mathrm{Rs}$, were similar in hypertensive and normotensive mice (fig. S11, A and B), indicating that the defect lies downstream of muscarinic receptors.

Because muscarinic receptor activation stimulated TRPV4 channels exclusively at MEPs (see Fig. 1 and fig. S3), Ang II-induced hypertension might affect TRPV4 function at MEPs without affecting the overall TRPV4 channel number. TRPV4 sparklet activity at MEPs under basal conditions (that is, in the absence of GSK101) was reduced ( 2.7-fold) in the ECs of mesenteric arteries from hypertensive mice compared with that in normotensive mice (10 to 13 arteries, $P<0.05 ; t$ test). In the presence of GSK101, TRPV4 sparklet activity per MEP site was lower in hypertensive mouse arteries than in arteries from normotensive mice, but the activity at non-MEP sites was not different (Fig. 6A). Moreover, four fluorescence levels were observed in all cases, indicating that the four-channel cluster architecture of TRPV4 channels was unaffected by hypertension. We further found that functional coupling among TRPV4 channels at MEPs in hypertensive mice was significantly weaker than that in normotensive mice (Fig. 6B), a finding consistent with the idea that the reduction in functional coupling in these mice is responsible for the reduction in sparklet activity (Fig. 3, $\mathrm{C}$ and $\mathrm{D}$ ). These changes in sparklet activity and functional coupling are also similar to those observed in the absence of AKAP150 (Fig. 3, D to F). Therefore, we tested whether muscarinic receptor activation and downstream signaling stimulated TRPV4 sparklets at MEPs in arteries from hypertensive mice. In contrast to arteries from normotensive mice, in which CCh or activation of PKC by PMA induced an increase in TRPV4 sparklets, neither CCh nor PMA induced TRPV4 sparklets in arteries from hypertensive mice (Fig. 6C).

Because AKAP150 at MEPs was essential for muscarinic receptor- mediated activation of TRPV4 channels and augmented TRPV4 channel cooperativity at MEPs, we hypothesized that AKAP150 localization at MEPs is disrupted in this hypertension model. Although the number of holes in the inner elastic lamina, where MEPs are found, was similar in normotensive and hypertensive mice (table S4), only $~ 15 \%$ of holes in hypertensive mouse arteries exhibited AKAP150 staining compared with $~ 93 \%$ in normotensive mice (Fig. 6, D and E, and movie S2). Furthermore, in normotensive mice, the centers of peak AKAP150 staining intensity closely aligned with holes in the inner elastic lamina. In contrast, peak AKAP150 staining intensity in hypertensive mice not only shifted away from holes, but most holes showed no identifiable AKAP150 staining (Fig. 6F).

To control for nonspecific effects of hypertension on antibody reactivity (for example, due to altered cellular architecture), we immunostained mesenteric arteries from normotensive and hypertensive mice for IK channels. These channels were not functionally affected by Ang II-induced hypertension (see Fig. 5C) and thus should exhibit similar staining in the arteries of normotensive and hypertensive mice. Indeed, the localization of IK channels at MEPs $(4,19,21)$ was similar in normotensive and hypertensive mice (fig. S11, C and D). These results support the concept that Ang II-induced hypertension is associated with a loss of AKAP150 localization at MEPs that diminishes TRPV4 channel cooperativ-ity and severs communication between $\mathrm{G}_{\mathrm{q}}$-coupled GPCRs and TRPV4 channels. 


\section{DISCUSSION}

Until recently, studies on the role of intracellular $\mathrm{Ca}^{2+}$ in endothelial-mediated dilation have generally focused on whole-cell increases in $\mathrm{EC} \mathrm{Ca}^{2+}$. However, there is a growing appreciation that local $\mathrm{Ca}^{2+}$ signals dictate cellular physiology $(4,6,19,33,50)$. Our results reinforce this view, providing support for the concept that a MEP-localized ion channel signaling network is a critical regulator of endothelium-dependent vascular function $(4,5$, 19, 22). Specifically, we showed that muscarinic receptor activation induces TRPV4 sparklets exclusively at MEPs through the PLC-DAG-PKC pathway. The PKC-anchoring protein AKAP150, which we found localized predominantly to MEPs, not only ensures proximity between PKC and TRPV4 channels but also facilitates coupling among TRPV4 channels at MEPs, enhancing cooperative gating and increasing $\mathrm{Ca}^{2+}$ influx into these microdomains. AKAP150 knockout markedly reduced and chelation of intracellular $\mathrm{Ca}^{2+}$ essentially eliminated functional coupling between TRPV4 channels, indicating that the interaction between AKAP150 and TRPV4 may be $\mathrm{Ca}^{2+}$-dependent. TRPV4-mediated $\mathrm{Ca}^{2+}$ influx, in turn, activates MEP-localized IK channels $(4,6)$, which ultimately mediate hyperpolarization of SMCs (6), thereby causing vasodilation by deactivating VDCCs in SMCs. The preferential localization of EDH signaling elements at MEPs was disrupted in a mouse model of Ang II-induced hypertension, resulting in a profound reduction in endothelial-dependent vasodilation.

Our finding that AKAP150 is localized at MEPs and is required for $\mathrm{CCh}$-induced activation of TRPV4 sparklets supports the hypothesis that AKAP150 is responsible for anchoring PKC at MEPs, providing a mechanism for the exclusive activation of TRPV4 sparklets at MEPs by CCh. Consistent with this hypothesis, CCh, OAG, and PMA did not activate TRPV4 sparklets at non-MEP sites, where AKAP150 was not abundant. A similar phenomenon has been reported in neurons, where mobilization of an AKAP150-anchored pool of PKC by muscarinic agonists suppresses KCNQ2 channel-mediated M currents (51). However, AKAP150 is not responsible for anchoring TRPV4 channels at MEPs or for the 4channel metastructure, because four-channel activity is observed at MEP sites in arteries of AKAP150-/- (fig. S6). One possible alternative candidate for clustering TRPV4 channels is caveolin-1, which co-localizes with TRPV4 in cultured ECs and is necessary for EDHdependent vasorelaxation and full TRPV4 activity (52).

Although TRPV4 channels exhibited coupled gating at both MEP and non-MEP sites, coupling was much stronger at MEPs, approximately doubling $\mathrm{Ca}^{2+}$ influx through TRPV channels in this microdomain. The localization of AKAP150 at MEPs and the elimination of the difference in coupling strength between MEP- and non-MEP-localized channels in AKAP150 $0^{-/}$mice indicate that the enhanced coupling strength of TRPV4 channels at MEPs depends on AKAP150. However, neither PKC inhibition nor activation affected the coupling strength of TRPV4 channels, arguing against a role for PKC in TRPV4 channel cooperativity. Instead, AKAP150 may facilitate communication between channels in a cluster by associating with the channels, an interpretation consistent with the observation that TRPV4 directly binds AKAP150 (53). However, the four-channel metastructure was preserved at non-MEP sites, in arteries from AKAP150-/- mice and in hypertension, suggesting that other structural elements are responsible for this clustering. Our finding that 
channel coupling was almost completely eliminated by the mobile $\mathrm{Ca}^{2+}$ buffer EGTA also supports a central role for local $\mathrm{Ca}^{2+}$ communication in potentiating channel gating among TRPV4 channels within a cluster. Thus, AKAP150 may interact with TRPV4 in a manner akin to that of an allosteric regulatory subunit to enhance TRPV4 channel activation by intracellular $\mathrm{Ca}^{2+}$.

Various mechanisms have been proposed to account for the loss of endothelial-dependent vasodilation to $\mathrm{ACh}$ in hypertension, including the $\mathrm{EDH}$ component $(26,29,31,32)$.

However, neither the GPCR-Ga ${ }_{\mathrm{q}}$-PKC-AKAP50-TRPV4-IK signaling pathway nor the spatial organization of the elements in this pathway has been explored in any animal model of hypertension. Our finding that the maximum current densities of individual ion channels in the EDH pathway (TRPV4 and IK channels) and the localization of IK channels at MEPs were not altered in hypertensive mice argues against altered ion channel abundance or presence at the plasma membrane as a primary cause of the observed endothelial dysfunction. Dilation in response to the IK and SK agonist, NS309, was also unaltered in vessels from hypertensive mice, confirming that communication from ECs to SMCs was intact in these mice, and that the defect was upstream of $\mathrm{K}^{+}$channels. Therefore, our finding that AKAP150 localization at MEPs was disrupted in the mesenteric arteries of hypertensive mice indicates that the loss of EDH dilation in these mice is caused by impaired signaling through the GPCR-Ga $\mathrm{q}_{\mathrm{q}}$-PKC-AKAP50-TRPV4-IK pathway, resulting in a loss of CChinduced $\mathrm{Ca}^{2+}$ sparklets and a reduction in TRPV4 functional coupling, possibly due to an altered spatial arrangement among components of the pathway. The absence of CChinduced TRPV4 sparklets in the arteries of hypertensive mice likely accounts for the loss of $\mathrm{EDH}$-dependent dilation in response to muscarinic receptor activation, whereas the reduction in functional coupling likely contributes to the attenuation of GSK101-induced dilation. Collectively, our results demonstrate that the disrupted MEP localization of AKAP150 in hypertensive mice is responsible for the loss of $\mathrm{Ca}^{2+}$ signaling at MEPs, which leads to a loss of EDH-mediated dilation to muscarinic receptor stimulation. Thus, MEPlocalized AKAP150 likely plays a critical role in endothelial- dependent increases in blood flow; its loss in hypertension would compromise tissue perfusion and could contribute to hypertension.

Left unanswered is the question of the molecular mechanism responsible for localizing AKAP150 specifically at MEPs. In neurons, post-synaptic targeting of AKAP150 depends on the binding of N-terminal basic domains to F-actin and the acidic phospholipid phosphoinositide 4,5-bisphosphate ( $\left.\mathrm{PIP}_{2}\right)$. These domains are also involved in mediating the interaction of AKAP150 with $\mathrm{Ca}^{2+}$-sensitive cadherins to promote targeting of AKAP150 to epithelial cell adherens junctions (54), which have features in common with the gap junctions that join ECs and SMCs (55). In a HEK (human embryonic kidney) cell expression system and in neurons, palmitoylation of two $\mathrm{N}$-terminal cysteine residues localizes exogenously expressed AKAP150 to lipid rafts $(56,57)$. This latter mechanism is intriguing because caveolae, a type of lipid raft enriched for proteins of the caveolin family [caveolin-1 in ECs $(52,58,59)]$, are present at MEPs $(50)$. AKAP150 binds caveolin-3 in cardiac myocytes (60), and caveolin-3 and caveolin-1 have binding partners in common, including eNOS (61) and $\beta_{1}$ in-tegrin (62). Thus, an interaction between AKAP150 and caveolin-1 in EC caveolae may anchor AKAP150 at MEPs. 
We conclude that AKAP150, TRPV4, and IK channels localize at MEPs, constituting a functional unit that amplifies the hyperpolarizing input from ECs to SMCs (Fig. 7). This unit

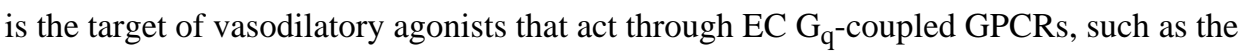
muscarinic ACh receptor. AKAP150 not only ensures $\mathrm{G}_{\mathrm{q}}$-coupled GPCR activation of TRPV4 channels at MEPs by anchoring PKC in proximity with TRPV4 channels but also enhances channel activity by promoting functional coupling between TRPV4 channels, a function that may involve a physical association between AKAP150 and TRPV4. Our results support the importance of local $\mathrm{Ca}^{2+}$ signaling within strategically positioned microdomains in controlling cell function. They also provide a signaling template for understanding how clustering of TRP channels with very considerable single-channel $\mathrm{Ca}^{2+}$ permeation (for example, TRPV1-4 and TRPA1) can selectively position and orchestrate channel activation without inducing $\mathrm{Ca}^{2+}$ overload.

\section{MATERIALS AND METHODS}

\section{Reagents}

GSK101 [N-((1S)-1-\{[4-((2S)-2-\{[(2,4-dichlorophenyl) sulfonyl] amino $\}-3$-hydroxypropanoyl)-1-piperazinyl]carbonyl \}-3-methylbutyl)-1-benzothiophene-2-carboxamide] was obtained from Sigma-Aldrich. CPA, U73122, PMA, OAG, and Gö-6976 were obtained from EMD Chemicals. HC-067047 (2-methyl-1-[3-(4-morpholinyl)propyl]-5-phenyl- $N$-[3(trifluoromethyl)phenyl]-1H-pyrrole-3-carboxamide) was a gift from Hydra Biosciences. Charybdotoxin and apamin were purchased from Peptide Institute and Enzo Life Sciences, respectively. All other chemicals were obtained from Sigma-Aldrich.

\section{Animal procedures}

Animal procedures used in this study are in accord with institutional guidelines and were approved by the Institutional Animal Care and Use Committee of the University of Vermont and University of Washington. Wild-type C57BL6/J, transgenic GCaMP2 ${ }^{\mathrm{Cx} 40}$, and AKAP150 ${ }^{-/}$(39) mice were used. GCaMP2 ${ }^{\mathrm{Cx} 40}$ mice express the circularly permutated, $\mathrm{Ca}^{2+}$ sensor GCaMP2 under the control of the connexin 40 (Cx40) promoter $(34,35)$, which limits expression of GCaMP2 to ECs in the vascular wall. Adult (3- to 4-month-old) male mice were euthanized by intraperitoneal injection of sodium pentobarbital $(150 \mathrm{mg} / \mathrm{kg})$ followed by a thoracotomy. Third-order branches of mesenteric arteries $(\sim 100-\mu \mathrm{m}$ internal diameter at $80 \mathrm{mmHg}$ ) were isolated into Hepes-buffered physiological salt solution (Hepes-PSS-1) consisting of $10 \mathrm{mM}$ Hepes, $134 \mathrm{mM} \mathrm{NaCl}, 6 \mathrm{mM} \mathrm{KCl}, 1 \mathrm{mM} \mathrm{MgCl} 2,2$ $\mathrm{mM} \mathrm{CaCl}_{2}, 7 \mathrm{mM}$ glucose, adjusted to $\mathrm{pH} 7.4$ with $\mathrm{NaOH}$. Arteries were used intact for pressurized artery studies or cut longitudinally and pinned to a SYLGARD block with the endothelium facing up for the en face preparation used for imaging of endothelial $\mathrm{Ca}^{2+}$ signals and AKAP150 immunostaining.

\section{Pressurized arteries}

Diameter measurements of pressurized arteries were performed as described previously (6, 33). Briefly, mesenteric arteries were dissected free of surrounding tissue and mounted on similar-sized glass pipettes in an arteriograph chamber (Living Systems Instrumentation). Arteries were then pressurized to $80 \mathrm{mmHg}$ for at least $45 \mathrm{~min}$ in prewarmed $\left(36^{\circ} \mathrm{C}\right) \mathrm{PSS}$ 
without Hepes [119 mM NaCl, $4.7 \mathrm{mM} \mathrm{KCl}, 1.2 \mathrm{mM} \mathrm{KH}_{2} \mathrm{PO}_{4}, 1.2 \mathrm{mM} \mathrm{MgCl} 2,2 \mathrm{mM}$ $\mathrm{CaCl}_{2}, 7 \mathrm{mM}$ glucose, $24 \mathrm{mM} \mathrm{NaHCO}_{3}$ (pH 7.4)], constantly bubbled with $20 \% \mathrm{O}_{2}$ and $5 \%$ $\mathrm{CO}_{2}$. Internal diameter was continuously monitored with a $\mathrm{CCD}$ (charge-coupled device) camera and edge-detection software (IonOptix). All compounds were added to the PSS, which was continuously recirculated through the arteriograph chamber. At the conclusion of each experiment, arteries were treated with $\mathrm{Ca}$-free PSS [119 mM NaCl, $4.7 \mathrm{mM} \mathrm{KCl}, 1.2$ $\mathrm{mM} \mathrm{KH} \mathrm{PO}_{4}, 1.2 \mathrm{mM} \mathrm{MgCl}_{2}, 7 \mathrm{mM}$ glucose, $24 \mathrm{mM} \mathrm{NaHCO}_{3}, 5 \mathrm{mM}$ EGTA (pH 7.4)] to obtain maximal dilation. Myogenic tone was calculated as follows:

$$
\left[\left(\text { Diameter }_{\mathrm{Ca} 2+- \text { free }}-\text { Diameter }_{\text {basal }}\right) / \text { Diameter }_{\mathrm{Ca} 2+- \text { free }}\right] \times 100
$$

where Diameter ${ }_{\text {basal }}$ is the basal diameter of the artery pressurized at $80 \mathrm{mmHg}$. Mesenteric artery dilation was expressed as follows:

$$
\left[\left(\text { Diameter }_{\text {dilated }}-\text { Diameter }_{\text {basal }}\right) /\left(\text { Diameter }_{\text {Ca2 }+- \text { free }}-\text { Diameter }_{\text {basal }}\right)\right] \times 100
$$

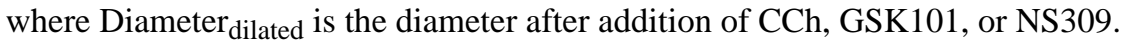

\section{EC patch clamp and calculation of channel number}

ECs were freshly isolated from third-order mesenteric arteries as described previously (6, $63,64)$. The mean membrane capacitance of ECs from normotensive mice was $14.6 \pm 0.7 \mathrm{pF}$ $(n=11$ cells) and that from hypertensive mice was $14.0 \pm 1.8 \mathrm{pF}(n=13$ cells). Macroscopic TRPV4, IK, and SK currents were recorded at $+100 \mathrm{mV}$ in freshly isolated ECs using the perforated-patch configuration and a bathing solution of Hepes-PSS-2 (same as HepesPSS-1 except containing $10 \mathrm{mM}$ glucose instead of $7 \mathrm{mM}$ glucose). The pipette solution consisted of $10 \mathrm{mM}$ Hepes, $30 \mathrm{mM} \mathrm{KCl}, 10 \mathrm{mM} \mathrm{NaCl}, 110 \mathrm{mM} \mathrm{K}$-aspartate, and $1 \mathrm{mM}$ $\mathrm{MgCl} 2$ (adjusted to $\mathrm{pH} 7.2$ with $\mathrm{NaOH}$ ).

Maximum TRPV4 channel currents were obtained by stimulation with 100 nM GSK101, as we have done previously (6). Maximum IK and SK currents were recorded using conventional whole-cell patch clamp of isolated ECs dialyzed with a pipette solution consisting of $10 \mathrm{mM}$ Hepes, $123.2 \mathrm{mM} \mathrm{KCl}, 10 \mathrm{mM} \mathrm{NaCl}, 5.5 \mathrm{mM} \mathrm{MgCl}, 0.2 \mathrm{mM} \mathrm{CaCl}_{2}$, and $5 \mathrm{mM}$ HEDTA (adjusted to $\mathrm{pH} 7.2$ with $16.8 \mathrm{mM} \mathrm{KOH}$ ) and containing $3 \mu \mathrm{M}$ free $\mathrm{Ca}^{2+}$ and $1 \mathrm{mM}$ free $\mathrm{Mg}^{2+}$, calculated using the Maxchelator program (C. Patton, Stanford University, CA, USA), to maximize channel activity $(6,63,64)$. The IK channel current was determined from the decrease in current after treatment with charybdotoxin, whereas SK channel current was determined from the further decrease in current with subsequent addition of apamin.

The relationship between any type of current and the membrane potential can be described by the Goldman-Hodgkin-Katz constant field equation $(65,66)$. For $\mathrm{K}^{+}$currents mediated by IK and SK channels, this relationship is expressed as follows:

$$
I_{\mathrm{K}}=P_{\mathrm{K}} \times \frac{E F^{2}}{R T} \frac{\left[\mathrm{K}^{+}\right]_{\mathrm{O}}-\left[\mathrm{K}^{+}\right]_{\mathrm{i}} \exp [E F /(R T)]}{1-\exp [E F /(R T)]}
$$


where $\mathrm{P}_{\mathrm{k}}$ is the permeability of the channel to $\mathrm{K}^{+}$ions (in $\mathrm{cm} / \mathrm{s}$ ); $\left[\mathrm{K}^{+}\right]_{\mathrm{o}}$ and $\left[\mathrm{K}^{+}\right]_{\mathrm{i}}$ are the concentrations of $\mathrm{K}^{+}$in the extracellular and intracellular compartments, respectively; $E$ is the membrane potential (in V); $F$ is the Faraday constant; $R$ is the gas constant; and $T$ is the temperature (in Kelvin). Values of single-channel permeability to $\mathrm{K}^{+}\left(P_{\mathrm{k}}\right)$, previously reported by our laboratory, are $8.7872 \times 10^{-14} \mathrm{~cm} / \mathrm{s}$ for IK channels and $2.1968 \times 10^{-14}$ $\mathrm{cm} / \mathrm{s}$ for SK channels (64). The number of IK and SK channels per EC was determined from the equation for macroscopic current, $I=N \times i \times P_{\mathrm{O}}$, where $N$ is the number of channels, $i$ is the single-channel current, and $P_{\mathrm{O}}$ is the open probability of the channel. The single-channel current $(i)$, calculated at $-70 \mathrm{mV}$ with $\left[\mathrm{K}^{+}\right]_{\mathrm{o}}=6 \mathrm{mM}$ and $\left[\mathrm{K}^{+}\right]_{\mathrm{i}}=140 \mathrm{mM}$, was $0.073 \mathrm{pA}$ for IK channels and $0.018 \mathrm{pA}$ for SK channels. The mean whole-cell (macroscopic) current $(I)$ at $-70 \mathrm{mV}$ was $38.67 \mathrm{pA}$ for IK channels $(n=6 \mathrm{ECs})$ and $4.88 \mathrm{pA}$ for SK channels $(n=5$ ECs). Previously published $P_{\mathrm{O}}$ values of $0.7(67,68)$ and $0.8(69)$ were used for IK and SK channels, respectively.

The number of TRPV4 channels per EC was calculated as described previously (6).

\section{$\mathrm{EC} \mathrm{Ca}{ }^{2+}$ imaging}

$\mathrm{Ca}^{2+}$ signals in ECs were imaged with a Revolution Andor confocal system (Andor Technology) composed of an upright Nikon microscope with a $60 \times$ water-dipping objective [numerical aperture (NA) 1.0] and an electron-multiplying CCD camera, as described previously $(4,6,33)$. Briefly, images were acquired at 15 frames/s for arteries from GCaMP2 mice and 30 frames/s for Fluo-4-loaded arteries using Andor Revolution TL acquisition software (Andor Technology). Changes in emission associated with $\mathrm{Ca}^{2+}$ binding were detected by exciting at $488 \mathrm{~nm}$ with a solid-state laser and collecting emitted fluorescence using a 527.5/49-nm band-pass filter, with a center wavelength of $527.5 \mathrm{~nm}$ and a guaranteed minimum bandwidth of $49 \mathrm{~nm}$. $\mathrm{Ca}^{2+}$ imaging experiments were performed at $36^{\circ} \mathrm{C}$. TRPV4 $\mathrm{Ca}^{2+}$ sparklets were analyzed within a ROI defined by a $1.7-\mu \mathrm{m}^{2}$ box $(5 \times 5$ pixels) positioned at a point corresponding to peak TRPV4 $\mathrm{Ca}^{2+}$ sparklet amplitude. In preparations from wild-type C57BL6 mice and AKAP150 $0^{-1}$ mice, ECs were loaded with Fluo-4 $(10 \mu \mathrm{M})$ by incubating for $45 \mathrm{~min}$ at $30^{\circ} \mathrm{C}$ in the presence of pluronic acid (2.5 $\mathrm{mg} / \mathrm{ml}$ ) before imaging. The field of view was $\sim 113 \times 136 \mu \mathrm{m}$, corresponding to $14.5 \pm 0.5$ cells per field ( $n=6$ fields). CPA ( $30 \mu \mathrm{M}, 15 \mathrm{~min}$ ) was included to eliminate $\mathrm{IP}_{3} \mathrm{R}$-mediated $\mathrm{Ca}^{2+}$ signaling. The images were recorded before and $5 \mathrm{~min}$ after treatment with CCh, PMA, or OAG. Gö-6976 (1 $\mu \mathrm{M}, 10 \mathrm{~min})$ was added before treatment with CCh, OAG, or PMA, and HC-067047 ( $1 \mu \mathrm{M}, 10 \mathrm{~min})$. Displayed $F / F_{0}$ traces were filtered using a Gaussian filter with a cutoff corner frequency of $3.98 \mathrm{~Hz}$. Corresponding $F / F_{0}$ traces shown in figures represent the same ROIs before and after treatment. MEPs were identified as black holes in the inner elastic lamina, corresponding to an absence of autofluorescence $(4,19,22)$. A diameter of $2 \mathrm{~mm}$, the dimension of the smallest holes in autofluorescence images, was used as a low-end cutoff for defining a hole. Sparklet sites at MEPs were identified as those with peak fluorescence within $5 \mathrm{~mm}$ of the center of a hole in the inner elastic lamina. Changes in activity were expressed as fold change relative to controls. 


\section{Immunostaining}

Surgically opened arteries were mounted on a silicone block and fixed with ice-cold acetone for $10 \mathrm{~min}$, permeabilized with $0.2 \%$ Triton $\mathrm{X}$, blocked with $5 \%$ normal donkey serum, and incubated with a polyclonal antibody specific for AKAP150 (sc-6445, 1:250; Santa Cruz Biotechnology Inc.), IK channels (APC-064, 1:500; Alomone Labs), or PKCa (sc-208; Santa Cruz Biotechnology Inc.) overnight at $4^{\circ} \mathrm{C}$. After five washes with phosphate-buffered saline (PBS), arteries were incubated with Alexa Fluor 568-conjugated donkey anti-goat or anti-rabbit secondary antibody (1:500; Life Technologies Corp.) for $90 \mathrm{~min}$ at room temperature. Arteries were imaged with a Revolution Andor confocal system as described above. Autofluorescence of the inner elastic lamina was assessed by exciting at $488 \mathrm{~nm}$ with a solid-state laser and collecting emitted fluorescence using a 527.5/49-nm band-pass filter. AKAP150 immunostaining was assessed by exciting at $560 \mathrm{~nm}$ and collecting emitted fluorescence using a 641.5/117-nm band-pass filter. The holes with AKAP150 immunostaining were identified as those with peak staining within $5 \mu \mathrm{m}$ of the center of a hole in the inner elastic lamina. For three-dimensional volume rendering, images were recorded in multiple optical planes along the $z$ axis at $0.1-\mu \mathrm{m}$ increments from the base of the endothelium to the surface of the smooth muscle. The z-resolution of the system was 1.2 $\mu \mathrm{m}$. Z-stack images were reconstructed using Andor iQ software. The number of MEPs with AKAP150 staining was expressed as a percentage of the total number of holes in the inner elastic lamina. We have routinely used this AKAP150 antibody (38) to immunostain for AKAP150 in SMCs, and have tested its specificity in AKAP150 ${ }^{-/-}$mice (60), using competing peptide (Santa Cruz Biotechnology) and by substitution with PBS. AKAP150associated immunostaining was absent under these conditions.

\section{Ang II infusion and blood pressure measurement}

Systolic blood pressure was recorded using tail-cuff plethysmography (Columbus Instruments). Briefly, 3- to 4-month-old mice were trained for 1 week (twice daily) before recording baseline systolic blood pressure for two consecutive days. For implanting osmotic minipumps, mice were anesthetized with 5\% isoflurane and maintained with $2 \%$ isoflurane inhalation in $100 \% \mathrm{O}_{2}$. Osmotic minipumps (ALZET 2004; Durect Corp.) containing Ang II (Bachem) were implanted subcutaneously as previously described (49). The Ang II infusion rate was $1.4 \mathrm{mg} / \mathrm{kg}$ per day. After recovery from anesthesia, mice were housed in individual cages and allowed free access to food and water. Systolic blood pressure recordings were continued on days $4,7,10,14,18$, and 21 after minipump implantation. The systolic blood pressures in mice infused with $0.9 \%$ saline for 3 weeks $(120.9 \pm 4.6 \mathrm{mmHg}, n=4$ mice) were not different from those of normal C57BL6/J mice. CCh $(1 \mu \mathrm{M})$-induced dilations in mesenteric arteries from saline-infused mice $(79.1 \pm 4.5 \%$ of maximum, $n=4)$ were also not different from those of normal C57BL6/J mice. Therefore, uninfused C57BL6/J mice were used as a control group for subsequent experiments.

\section{Calculation of TRPV4 sparklet activity}

TRPV4 sparklet activity was analyzed using custom-designed software written by A. Bonev as previously described (6). Fractional fluorescence $\left(F / F_{0}\right)$ at a site was obtained by dividing the fluorescence of an ROI in the collected image by the average fluorescence of 10 images 
without activity from the same ROI. Area under the curve (AUC) for each event was calculated using trapezoidal numerical integration ( $\left[F-F_{0}\right] / F_{0}$ over time, in seconds). Activity at a TRPV4Ca ${ }^{2+}$ sparklet site was determined as the sum of AUCs of all events at that site within a 2-min recording duration. The activity integrals from all sparklet sites in a field were added to obtain total sparklet activity for that field. Sparklet activity per field was compared before and after a treatment in paired experiments. Similarly, activity integrals from all sparklet sites in a field were averaged to obtain activity per site for that field.

\section{Estimation of $P_{\mathrm{O}}$ and channel activity (NPO) of TRPV4 channels at a sparklet site}

The average number of active TRPV 4 channels, $N P_{\mathrm{O}}\left(N\right.$, number of channels; $P_{\mathrm{O}}$, observed open probability), calculated as

$$
N P_{\mathrm{O}}=\left(T_{\text {level } 1}+2 T_{\text {level } 2}+3 T_{\text {level } 3}+4 T_{\text {level } 4}\right) / T_{\text {total }}
$$

where $T$ is the dwell time at each quantal level observed at MEP and non-MEP sparklet sites and $T_{\text {total }}$ is duration of the recording, was determined using the Single Channel Search module of Clampfit and known quantal amplitudes from all-points histograms $\left(\Delta F / F_{0}\right.$ of 0.19 for GCaMP2 mice and 0.29 for Fluo-4-loaded arteries) (6). $N P_{\mathrm{O}}$ per site was obtained by averaging $N P_{\mathrm{O}}$ for all the sites in a field. The $N P_{\mathrm{O}}$ values per site from 3 to 10 fields were averaged to obtain the mean $N P_{\mathrm{O}}$ per site. $N P_{\mathrm{O}}$ per cell or per field was estimated in a similar manner by summing $N P_{\mathrm{O}}$ per site over an entire cell or field respectively. The experimentally observed $P_{\mathrm{O}}$ at a sparklet site was determined by dividing $N P_{\mathrm{O}}$ at that site by 4 , the maximum number of quantal levels (channels) observed at MEP and non-MEP sites.

\section{Estimating the contribution of cooperative gating to $\mathrm{Ca}^{2+}$ influx through TRPV4 channels}

The boost in TRPV4 channel activity at a sparklet site due to cooperative gating was determined by estimating the probability of independent channel gating. The probability that $i$ channels are open in a cluster of $N$ independent channels can be calculated from the binomial distribution (6),

$$
P(i)=[N ! /(N-1) ! i !] \times p_{\mathrm{O}}^{i} \times\left(1-P_{\mathrm{O}}\right)^{N-i}
$$

where $N$ is the number of identical and independent channels (fixed at 4 per site based on experimental data) and $P_{\mathrm{O}}$ is the open probability of a channel gating independently. We found that $P$ of the first level was similar regardless of the condition (MEP, non-MEP, AKAP150 $0^{-/}$, and hypertension), suggesting that the opening of one channel in a sparklet site reflects independent gating. However, the probability of 2,3 , and 4 levels is not independent (6). Therefore, we used the above equation to estimate channel $P_{\mathrm{O}}$ in the absence of cooperativity by iterating $P_{\mathrm{O}}$ to obtain the experimentally observed probability of the first level (one channel open), using $n=4$. The boost in channel activity $\left(\mathrm{Ca}^{2+}\right.$ influx) attributable to cooperativity was estimated by dividing the experimentally observed $\mathrm{PO}$ by the channel open probability from the binomial distribution, assuming independence (fig. S7). 


\section{Calculation of coupling coefficient $(x)$ of TRPV4 sparklets}

A coupled Markov chain model in MATLAB was implemented to determine the coupling coefficient among TRPV4 channels on EC membranes, as previously described $(37,41)$. [F $\left.-F_{0}\right] / F_{0}$ traces with at least $30 \mathrm{~s}$ of steady baseline were used for analyses. Each TRPV4 sparklet site was analyzed separately. The coupled Markov chain model was originally described by Chung and Kennedy (40) to simulate and fit independent records of partially coupled channels. Using a program written in MATLAB language, single-channel openings were identified using a half-amplitude protocol, with the quantal level of a unitary event set at $0.19 \Delta F / F_{0}$ for GCaMP2 mouse arteries and $0.29 \Delta F / F_{0}$ for Fluo-4-loaded arteries. The activity of TRPV4 channels was modeled as a first-order, discrete Markov chain, and a Markovian transition matrix was estimated from the sparklet records and their corresponding channel opening time courses using the built-in Hidden Markov parameter estimation function in MATLAB. The estimated transition matrix was modeled as a partially coupled Markov chain, where the coupling coefficient $(\kappa)$ is a dimensionless parameter that may vary from 0 , for channels that show no coupling (independent gating), to 1 , for fully coupled channels. The model also has two additional parameters: $\rho$, the channel open-to-open probability, and $\zeta$, the channel closed-to-closed probability. Together, these three parameters fully describe the contribution of fully uncoupled channels to the transition matrix. The optimum set of parameters $(\kappa, \rho, \zeta)$ for the partially coupled Markov chain model was fitted using a gradient descent algorithm for each record. This is a "lumped" model, in which the channels switch between the observable states of "open" and "closed"; therefore, our model has only three free parameters, including the coupling coefficient. It does not completely describe the actual kinetics of the channel. Therefore, the transition probabilities obtained from this lumped model are not interpreted as rate constants.

\section{Statistics}

Data are expressed as means \pm SEM. Student's $t$ test and one-way ANOVA with post hoc Bonferroni tests were used for comparisons between two groups and among more than two groups, respectively. A $P$ value less that 0.05 was considered significant.

\section{Supplementary Material}

Refer to Web version on PubMed Central for supplementary material.

\section{Acknowledgments}

We thank Hydra Biosciences for HC-067047, NeuroSearch A/S for NS309, R. Dixon and S. Renjitham for help with coupling coefficient analyses, C. Yuan for help with AKAP150 antibody, and J. Brayden, K. Freeman, M. Koide, and G. Wellman for comments on the manuscript. Funding: This work was supported by a grant from the COBRE (Centers of Biomedical Research Excellence) Program of the National Center for Research Resources funded by the NIH (2-P20-RR-016435-06); an American Heart Association (AHA) Scientist Development Grant (13SDG16470005) and AHA-Pulmonary Hypertension Association postdoctoral fellowship (10POST3690006) to S.K.S.; a postdoctoral fellowship from the Lundbeck Foundation to T.D.; grants from the NIH to J.D.S. (R37GM48231) and M.I.K. (GM086736); and grants from the NIH (HL044455, 1P01HL095488, R37DK053832, and R01HL098243), Totman Medical Research Trust, and Fondation Leducq to M.T.N. 


\section{REFERENCES AND NOTES}

1. Furchgott RF, Zawadzki JV. The obligatory role of endothelial cells in the relaxation of arterial smooth muscle by acetylcholine. Nature. 1980; 288:373-376. [PubMed: 6253831]

2. Dora KA. Coordination of vasomotor responses by the endothelium. Circ. J. 2010; 74:226-232. [PubMed: 20065608]

3. Fukao M, Hattori Y, Kanno M, Sakuma I, Kitabatake A. Sources of $\mathrm{Ca}^{2+}$ in relation to generation of acetylcholine-induced endothelium-dependent hyperpolarization in rat mesenteric artery. Br. J. Pharmacol. 1997; 120:1328-1334. [PubMed: 9105709]

4. Ledoux J, Taylor MS, Bonev AD, Hannah RM, Solodushko V, Shui B, Tallini Y, Kotlikoff MI, Nelson MT. Functional architecture of inositol 1,4,5-trisphosphate signaling in restricted spaces of myoendothelial projections. Proc. Natl. Acad. Sci. U.S.A. 2008; 105:9627-9632. [PubMed: 18621682]

5. Sandow SL, Senadheera S, Grayson TH, Welsh DG, Murphy TV. Calcium and endotheliummediated vasodilator signaling. Adv. Exp. Med. Biol. 2012; 740:811-831. [PubMed: 22453971]

6. Sonkusare SK, Bonev AD, Ledoux J, Liedtke W, Kotlikoff MI, Heppner TJ, Hill-Eubanks DC, Nelson MT. Elementary $\mathrm{Ca}^{2+}$ signals through endothelial TRPV4 channels regulate vascular function. Science. 2012; 336:597-601. [PubMed: 22556255]

7. Earley S, Pauyo T, Drapp R, Tavares MJ, Liedtke W, Brayden JE. TRPV4-dependent dilation of peripheral resistance arteries influences arterial pressure. Am. J. Physiol. Heart Circ. Physiol. 2009; 297:H1096-H1102. [PubMed: 19617407]

8. Hartmannsgruber V, Heyken WT, Kacik M, Kaistha A, Grgic I, Harteneck C, Liedtke W, Hoyer J, Köhler R. Arterial response to shear stress critically depends on endothelial TRPV4 expression. PLOS One. 2007; 2:e827. [PubMed: 17786199]

9. Köhler R, Heyken WT, Heinau P, Schubert R, Si H, Kacik M, Busch C, Grgic I, Maier T, Hoyer J. Evidence for a functional role of endothelial transient receptor potential V4 in shear stress-induced vasodilatation. Arterioscler. Thromb. Vasc. Biol. 2006; 26:1495-1502. [PubMed: 16675722]

10. Marrelli SP, O’Neil G, Brown RC, Bryan RM Jr. PLA 2 and TRPV4 channels regulate endothelial calcium in cerebral arteries. Am. J. Physiol. Heart Circ. Physiol. 2007; 292:H1390-H1397. [PubMed: 17071727]

11. Mendoza SA, Fang J, Gutterman DD, Wilcox DA, Bubolz AH, Li R, Suzuki M, Zhang DX. TRPV4-mediated endothelial $\mathrm{Ca}^{2+}$ influx and vasodilation in response to shear stress. Am. J. Physiol. Heart Circ. Physiol. 2010; 298:H466-H476. [PubMed: 19966050]

12. Zhang DX, Mendoza SA, Bubolz AH, Mizuno A, Ge ZD, Li R, Warltier DC, Suzuki M, Gutterman DD. Transient receptor potential vanilloid type 4-deficient mice exhibit impaired endothelium-dependent relaxation induced by acetylcholine in vitro and in vivo. Hypertension. 2009; 53:532-538. [PubMed: 19188524]

13. Earley S, Gonzales AL, Crnich R. Endothelium-dependent cerebral artery dilation mediated by TRPA1 and $\mathrm{Ca}^{2+}$-activated $\mathrm{K}^{+}$channels. Circ. Res. 2009; 104:987-994. [PubMed: 19299646]

14. Earley S, Gonzales AL, Garcia ZI. A dietary agonist of transient receptor potential cation channel V3 elicits endothelium-dependent vasodilation. Mol. Pharmacol. 2010; 77:612-620. [PubMed: 20086034]

15. Fleming I, Busse R. NO: The primary EDRF. J. Mol. Cell. Cardiol. 1999; 31:5-14. [PubMed: 10072711]

16. Bogatcheva NV, Sergeeva MG, Dudek SM, Verin AD. Arachidonic acid cascade in endothelial pathobiology. Microvasc. Res. 2005; 69:107-127. [PubMed: 15896353]

17. Coleman HA, Tare M, Parkington HC. Endothelial potassium channels, endothelium-dependent hyperpolarization and the regulation of vascular tone in health and disease. Clin. Exp. Pharmacol. Physiol. 2004; 31:641-649. [PubMed: 15479173]

18. Edwards G, Félétou M, Weston AH. Endothelium-derived hyperpolarising factors and associated pathways: A synopsis. Pflugers Arch. 2010; 459:863-879. [PubMed: 20383718]

19. Bagher P, Beleznai T, Kansui Y, Mitchell R, Garland CJ, Dora KA. Low intra-vascular pressure activates endothelial cell TRPV4 channels, local $\mathrm{Ca}^{2+}$ events, and IKCa channels, reducing arteriolar tone. Proc. Natl. Acad. Sci. U.S.A. 2012; 109:18174-18179. [PubMed: 23071308] 
20. Dora KA, Sandow SL, Gallagher NT, Takano H, Rummery NM, Hill CE, Garland CJ. Myoendothelial gap junctions may provide the pathway for EDHF in mouse mesenteric artery. $\mathrm{J}$. Vasc. Res. 2003; 40:480-490. [PubMed: 14583659]

21. Sandow SL, Neylon CB, Chen MX, Garland CJ. Spatial separation of endo-thelial small- and intermediate-conductance calcium-activated potassium channels $\left(\mathrm{K}_{\mathrm{Ca}}\right)$ and connexins: Possible relationship to vasodilator function? J. Anat. 2006; 209:689-698. [PubMed: 17062025]

22. Sandow SL, Senadheera S, Bertrand PP, Murphy TV, Tare M. Myoendothelial contacts, gap junctions, and microdomains: Anatomical links to function? Microcirculation. 2012; 19:403-415. [PubMed: 22074364]

23. Adapala RK, Talasila PK, Bratz IN, Zhang DX, Suzuki M, Meszaros JG, Thodeti CK. PKCa mediates acetylcholine-induced activation of TRPV4-dependent calcium influx in endothelial cells. Am. J. Physiol. Heart Circ. Physiol. 2011; 301:H757-H765. [PubMed: 21705673]

24. Fan HC, Zhang X, McNaughton PA. Activation of the TRPV4 ion channel is enhanced by phosphorylation. J. Biol. Chem. 2009; 284:27884-27891. [PubMed: 19661060]

25. Büssemaker E, Popp R, Fisslthaler B, Larson CM, Fleming I, Busse R, Brandes RP. Aged spontaneously hypertensive rats exhibit a selective loss of EDHF-mediated relaxation in the renal artery. Hypertension. 2003; 42:562-568. [PubMed: 12925561]

26. Dal-Ros S, Bronner C, Schott C, Kane MO, Chataigneau M, Schini-Kerth VB, Chataigneau T. Angiotensin II-induced hypertension is associated with a selective inhibition of endotheliumderived hyperpolarizing factor-mediated responses in the rat mesenteric artery. J. Pharmacol. Exp. Ther. 2009; 328:478-486. [PubMed: 18984652]

27. Félétou M, Köhler R, Vanhoutte PM. Endothelium-derived vasoactive factors and hypertension: Possible roles in pathogenesis and as treatment targets. Curr. Hypertens. Rep. 2010; 12:267-275. [PubMed: 20532699]

28. Giachini FR, Carneiro FS, Lima VV, Carneiro ZN, Dorrance A, Webb RC, Tostes RC. Upregulation of intermediate calcium-activated potassium channels counterbalance the impaired endothelium-dependent vasodilation in stroke-prone spontaneously hypertensive rats. Transl. Res. 2009; 154:183-193. [PubMed: 19766962]

29. Grgic I, Kaistha BP, Hoyer J, Köhler R. Endothelial $\mathrm{Ca}^{2+}$-activated $\mathrm{K}^{+}$channels in normal and impaired EDHF-dilator responses-Relevance to cardiovascular pathologies and drug discovery. Br. J. Pharmacol. 2009; 157:509-526. [PubMed: 19302590]

30. Toque HA, Nunes KP, Rojas M, Bhatta A, Yao L, Xu Z, Romero MJ, Webb RC, Caldwell RB, Caldwell RW. Arginase 1 mediates increased blood pressure and contributes to vascular endothelial dysfunction in deoxycorticosterone acetate-salt hypertension. Front. Immunol. 2013; 4:219. [PubMed: 23908657]

31. Weston AH, Porter EL, Harno E, Edwards G. Impairment of endothelial $\mathrm{SK}_{\mathrm{Ca}}$ channels and of downstream hyperpolarizing pathways in mesenteric arteries from spontaneously hypertensive rats. Br. J. Pharmacol. 2010; 160:836-843. [PubMed: 20233221]

32. Hilgers RH, Webb RC. Reduced expression of $\mathrm{SK}_{\mathrm{Ca}}$ and $\mathrm{IK}_{\mathrm{Ca}}$ channel proteins in rat small mesenteric arteries during angiotensin II-induced hypertension. Am. J. Physiol. Heart Circ. Physiol. 2007; 292:H2275-H2284. [PubMed: 17209000]

33. Nausch LW, Bonev AD, Heppner TJ, Tallini Y, Kotlikoff MI, Nelson MT. Sympathetic nerve stimulation induces local endothelial $\mathrm{Ca}^{2+}$ signals to oppose vaso-constriction of mouse mesenteric arteries. Am. J. Physiol. Heart Circ. Physiol. 2012; 302:H594-H602. [PubMed: 22140050]

34. Tallini YN, Brekke JF, Shui B, Doran R, Hwang SM, Nakai J, Salama G, Segal SS, Kotlikoff MI. Propagated endothelial $\mathrm{Ca}^{2+}$ waves and arteriolar dilation in vivo: Measurements in $\mathrm{Cx}_{40}{ }^{\mathrm{BAC}}$ GCaMP2 transgenic mice. Circ. Res. 2007; 101:1300-1309. [PubMed: 17932328]

35. Tallini YN, Ohkura M, Choi BR, Ji G, Imoto K, Doran R, Lee J, Plan P, Wilson J, Xin HB, Sanbe A, Gulick J, Mathai J, Robbins J, Salama G, Nakai J, Kotlikoff MI. Imaging cellular signals in the heart in vivo: Cardiac expression of the high-signal $\mathrm{Ca}^{2+}$ indicator GCaMP2. Proc. Natl. Acad. Sci. U.S.A. 2006; 103:4753-4758. [PubMed: 16537386]

36. Scott JD, Santana LF. A-kinase anchoring proteins: Getting to the heart of the matter. Circulation. 2010; 121:1264-1271. [PubMed: 20231544] 
37. Cheng EP, Yuan C, Navedo MF, Dixon RE, Nieves-Cintrón M, Scott JD, Santana LF. Restoration of normal L-type $\mathrm{Ca}^{2+}$ channel function during Timothy syndrome by ablation of an anchoring protein. Circ. Res. 2011; 109:255-261. [PubMed: 21700933]

38. Navedo MF, Nieves-Cintrón M, Amberg GC, Yuan C, Votaw VS, Lederer WJ, McKnight GS, Santana LF. AKAP150 is required for stuttering persistent $\mathrm{Ca}^{2+}$ sparklets and angiotensin IIinduced hypertension. Circ. Res. 2008; 102:e1-e11. [PubMed: 18174462]

39. Tunquist BJ, Hoshi N, Guire ES, Zhang F, Mullendorff K, Langeberg LK, Raber J, Scott JD. Loss of AKAP150 perturbs distinct neuronal processes in mice. Proc. Natl. Acad. Sci. U.S.A. 2008; 105:12557-12562. [PubMed: 18711127]

40. Chung SH, Kennedy RA. Coupled Markov chain model: Characterization of membrane channel currents with multiple conductance sublevels as partially coupled elementary pores. Math. Biosci. 1996; 133:111-137. [PubMed: 8718705]

41. Navedo MF, Cheng EP, Yuan C, Votaw S, Molkentin JD, Scott JD, Santana LF. Increased coupled gating of L-type $\mathrm{Ca}^{2+}$ channels during hypertension and Timothy syndrome. Circ. Res. 2010; 106:748-756. [PubMed: 20110531]

42. Strotmann R, Schultz G, Plant TD. $\mathrm{Ca}^{2+}$-dependent potentiation of the nonselective cation channel TRPV4 is mediated by a C-terminal calmodulin binding site. J. Biol. Chem. 2003; 278:2654126549. [PubMed: 12724311]

43. Watanabe H, Vriens J, Janssens A, Wondergem R, Droogmans G, Nilius B. Modulation of TRPV4 gating by intra- and extracellular $\mathrm{Ca}^{2+}$ Cell Calcium. 2003; 33:489-495. [PubMed: 12765694]

44. De Vriese AS, Van de Voorde J, Blom HJ, Vanhoutte PM, Verbeke M, Lameire NH. The impaired renal vasodilator response attributed to endothelium-derived hyperpolariz-ing factor in streptozotocin-Induced diabetic rats is restored by 5-methyltetrahydrofolate. Diabetologia. 2000; 43:1116-1125. [PubMed: 11043857]

45. Fitzgerald SM, Kemp-Harper BK, Tare M, Parkington HC. Role of endothelium-derived hyperpolarizing factor in endothelial dysfunction during diabetes. Clin. Exp. Pharmacol. Physiol. 2005; 32:482-487. [PubMed: 15854163]

46. Köhler R, Eichler I, Schönfelder H, Grgic I, Heinau P, Si H, Hoyer J. Impaired EDHF-mediated vasodilation and function of endothelial Ca-activated $\mathrm{K}$ channels in uremic rats. Kidney Int. 2005; 67:2280-2287. [PubMed: 15882269]

47. Ma X, Du J, Zhang P, Deng J, Liu J, Lam FF, Li RA, Huang Y, Jin J, Yao X. Functional role of TRPV4- $\mathrm{K}_{\mathrm{Ca}} 2.3$ signaling in vascular endothelial cells in normal and streptozotocin-induced diabetic rats. Hypertension. 2013; 62:134-139. [PubMed: 23648706]

48. Young EJ, Hill MA, Wiehler WB, Triggle CR, Reid JJ. Reduced EDHF responses and connexin activity in mesenteric arteries from the insulin-resistant obese Zucker rat. Diabetologia. 2008; 51:872-881. [PubMed: 18324386]

49. Kharade SV, Sonkusare SK, Srivastava AK, Thakali KM, Fletcher TW, Rhee SW, Rusch NJ. The $\beta 3$ subunit contributes to vascular calcium channel upregulation and hypertension in angiotensin II-infused C57BL/6 mice. Hypertension. 2013; 61:137-142. [PubMed: 23129698]

50. Tran CH, Taylor MS, Plane F, Nagaraja S, Tsoukias NM, Solodushko V, Vigmond EJ, Furstenhaupt T, Brigdan M, Welsh DG. Endothelial $\mathrm{Ca}^{2+}$ wavelets and the induction of myoendothelial feedback. Am. J. Physiol. Cell Physiol. 2012; 302:C1226-C1242. [PubMed: 22277756]

51. Hoshi N, Zhang JS, Omaki M, Takeuchi T, Yokoyama S, Wanaverbecq N, Langeberg LK, Yoneda Y, Scott JD, Brown DA, Higashida H. AKAP150 signaling complex promotes suppression of the M-current by muscarinic agonists. Nat. Neurosci. 2003; 6:564-571. [PubMed: 12754513]

52. Saliez J, Bouzin C, Rath G, Ghisdal P, Desjardins F, Rezzani R, Rodella LF, Vriens J, Nilius B, Feron O, Balligand JL, Dessy C. Role of caveolar compart-mentation in endothelium-derived hyperpolarizing factor-mediated relaxation: $\mathrm{Ca}^{2+}$ signals and gap junction function are regulated by caveolin in endothelial cells. Circulation. 2008; 117:1065-1074. [PubMed: 18268148]

53. Zhang X, Li L, McNaughton PA. Proinflammatory mediators modulate the heat-activated ion channel TRPV1 via the scaffolding protein AKAP79/150. Neuron. 2008; 59:450-461. [PubMed: 18701070] 
54. Gorski JA, Gomez LL, Scott JD, Dell'Acqua ML. Association of an A-kinase-anchoring protein signaling scaffold with cadherin adhesion molecules in neurons and epithelial cells. Mol. Biol. Cell. 2005; 16:3574-3590. [PubMed: 15930126]

55. Segal SS, Bagher P. Regulation of myoendothelial junction formation: Bridging the gap. Circ. Res. 2010; 106:1014-1016. [PubMed: 20360262]

56. Delint-Ramirez I, Willoughby D, Hammond GV, Ayling LJ, Cooper DM. Palmitoylation targets AKAP79 protein to lipid rafts and promotes its regulation of calcium-sensitive ade-nylyl cyclase type 8. J. Biol. Chem. 2011; 286:32962-32975. [PubMed: 21771783]

57. Keith DJ, Sanderson JL, Gibson ES, Woolfrey KM, Robertson HR, Olszewski K, Kang R, ElHusseini A, L Dell'acqua M. Palmitoylation of A-kinase anchoring protein 79/150 regulates dendritic endosomal targeting and synaptic plasticity mechanisms. J. Neurosci. 2012; 32:7119_ 7136. [PubMed: 22623657]

58. Drab M, Verkade P, Elger M, Kasper M, Lohn M, Lauterbach B, Menne J, Lindschau C, Mende F, Luft FC, Schedl A, Haller H, Kurzchalia TV. Loss of caveolae, vascular dysfunction, and pulmonary defects in caveolin-1 gene-disrupted mice. Science. 2001; 293:2449-2452. [PubMed: 11498544]

59. Lin Y, Jiang W, Ng J, Jina A, Wang RA. Endothelial ephrin-b2 is essential for arterial vasodilation in mice. 2014 Microcirculation 10.1111/micc.12135.

60. Nichols CB, Rossow CF, Navedo MF, Westenbroek RE, Catterall WA, Santana LF, McKnight GS. Sympathetic stimulation of adult cardiomyocytes requires association of AKAP5 with a subpopulation of L-type calcium channels. Circ. Res. 2010; 107:747-756. [PubMed: 20671242]

61. Feron O, Belhassen L, Kobzik L, Smith TW, Kelly RA, Michel T. Endothelial nitric oxide synthase targeting to caveolae. Specific interactions with caveolin isoforms in cardiac myocytes and endothelial cells. J. Biol. Chem. 1996; 271:22810-22814. [PubMed: 8798458]

62. Schwab W, Kasper M, Gavlik JM, Schulze E, Funk RH, Shakibaei M. Characterization of caveolins from human knee joint catilage: Expression of caveolin-1, -2 , and -3 in chondrocytes and association with integrin $\beta_{1}$. Histochem. Cell Biol. 2000; 113:221-225. [PubMed: 10817676]

63. Hannah RM, Dunn KM, Bonev AD, Nelson MT. Endothelial $\mathrm{SK}_{\mathrm{Ca}}$ and $\mathrm{IK}_{\mathrm{Ca}}$ channels regulate brain parenchymal arteriolar diameter and cortical cerebral blood flow. J. Cereb. Blood Flow Metab. 2011; 31:1175-1186. [PubMed: 21179072]

64. Ledoux J, Bonev AD, Nelson MT. $\mathrm{Ca}^{2+}$-activated $\mathrm{K}_{+}$channels in murine endothelial cells: Block by intracellular calcium and magnesium. J. Gen. Physiol. 2008; 131:125-135. [PubMed: 18195387]

65. Goldman DE. Potential, impedance, and rectification in membranes. J. Gen. Physiol. 1943; 27:3760. [PubMed: 19873371]

66. Hodgkin AL, Katz B. The effect of sodium ions on the electrical activity of giant axon of the squid. J. Physiol. 1949; 108:37-77. [PubMed: 18128147]

67. Bychkov R, Burnham MP, Richards GR, Edwards G, Weston AH, Félétou M, Vanhoutte PM. Characterization of a charybdotoxin-sensitive intermediate conductance $\mathrm{Ca}^{2+}$-activated $\mathrm{K}^{+}$ channel in porcine coronary endothelium: Relevance to EDHF. Br. J. Pharmacol. 2002; 137:13461354. [PubMed: 12466245]

68. Gao Y, Chotoo CK, Balut CM, Sun F, Bailey MA, Devor DC. Role of S3 and S4 transmembrane domain charged amino acids in channel biogenesis and gating of $\mathrm{KCa} 2.3$ and KCa3.1. J. Biol. Chem. 2008; 283:9049-9059. [PubMed: 18227067]

69. Hirschberg B, Maylie J, Adelman JP, Marrion NV. Gating of recombinant small-conductance Caactivated $\mathrm{K}^{+}$channels by calcium. J. Gen. Physiol. 1998; 111:565-581. [PubMed: 9524139] 
A

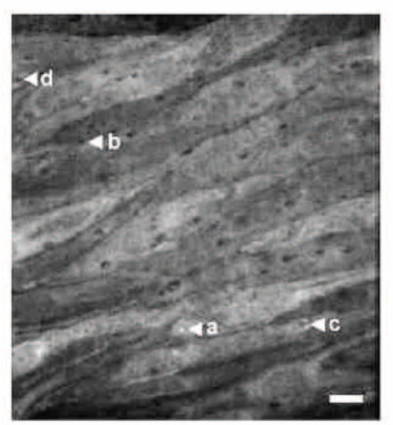

B

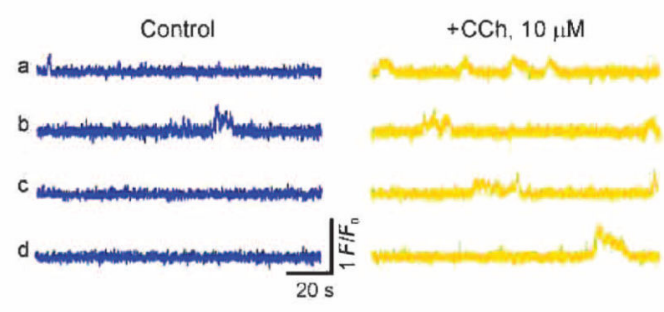

C

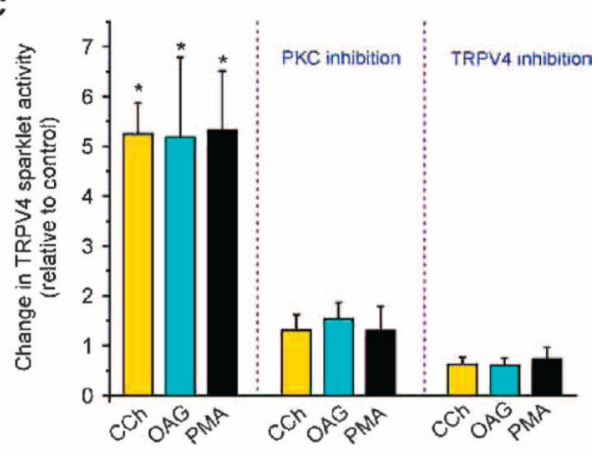

D

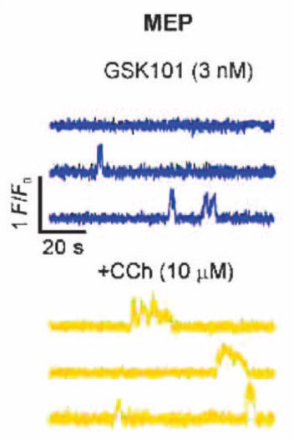

Non-MEP

GSK101 (3 nM)

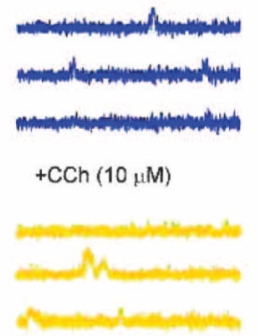

$\mathrm{E}$

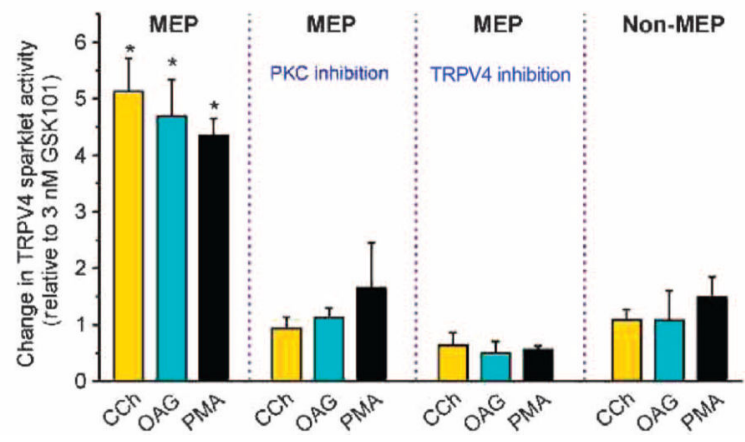

Fig. 1. CCh activates TRPV4 sparklets at MEPs through the PLC-DAG-PKC pathway TRPV4 $\mathrm{Ca}^{2+}$ sparklets were recorded in en face preparations of mesenteric arteries from GCaMP2 mice in the presence of CPA $(30 \mu \mathrm{M})$. (A) Grayscale image showing ECs in a field of view. The black holes in the internal elastic lamina correspond to sites where MEPs are located. The letter-labeled white arrows indicate four different TRPV4 sparklet sites at MEPs. (B) Representative $F / F_{0}$ traces from the TRPV4 sparklet sites at MEPs indicated in (A) under basal conditions before (control) and after CCh addition. (C) Bar graph summarizing the effects of $\mathrm{CCh}(10 \mu \mathrm{M}), \mathrm{OAG}(10 \mu \mathrm{M})$, and PMA $(10 \mathrm{nM})$ on TRPV4 sparklet activity at MEP sites in the presence or absence of the PKC inhibitor Gö-6976 (1 $\mu \mathrm{M})$ or the TRPV4 inhibitor HC-067047 (1 $\mu \mathrm{M})$. CPA-only was used as a control except in the PKC inhibition group, where CPA + Gö-6976 was used as a control. Data are means \pm SEM ( $n=5$ to 10 fields). (D) Representative $F / F_{0}$ traces from three different MEP and nonMEP sparklet sites before (blue) and after (yellow) CCh addition in the presence of $3 \mathrm{nM}$ GSK101. (E) Bar graph summarizing the effects of CCh, OAG, and PMA on TRPV4 sparklets at MEP and non-MEP sites in the presence of GSK101 (3 nM) and in the presence or absence of Gö-6976 or HC-067047. Data are means \pm SEM ( $n=4$ to 7 fields). Sparklet activity in the presence of CPA $(30 \mu \mathrm{M})$ and GSK101 $(3 \mathrm{nM})$ was used as a control, except for the PKC inhibition group, where sparklet activity in the presence of CPA, GSK101, and Gö-6976 was used as a control. In (C) and (E), Gö-6976 was added 10 min before CCh, OAG, or PMA treatment, whereas HC-067047 was added after CCh, OAG, or PMA (for 10 $\min$ ). $* P<0.05$ for columns 1 to 3 versus control and versus columns 7 to 9 [one-way analysis of variance (ANOVA) with post hoc Bonferroni test]. 
A

IEL autofluorescence

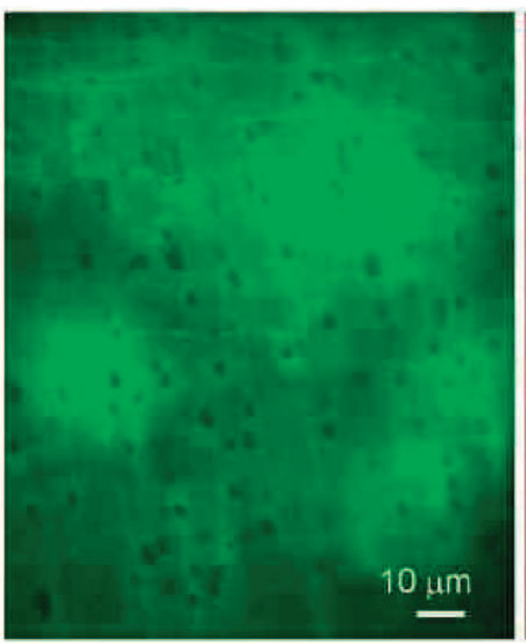

B
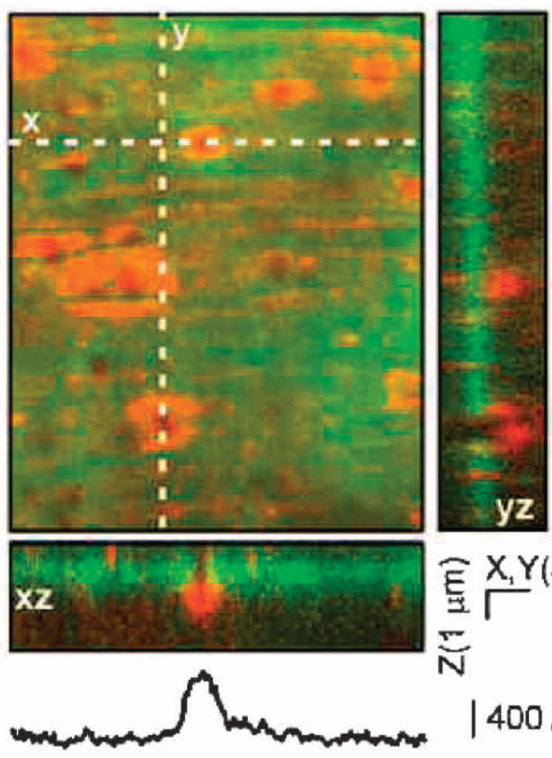

N
AKAP150

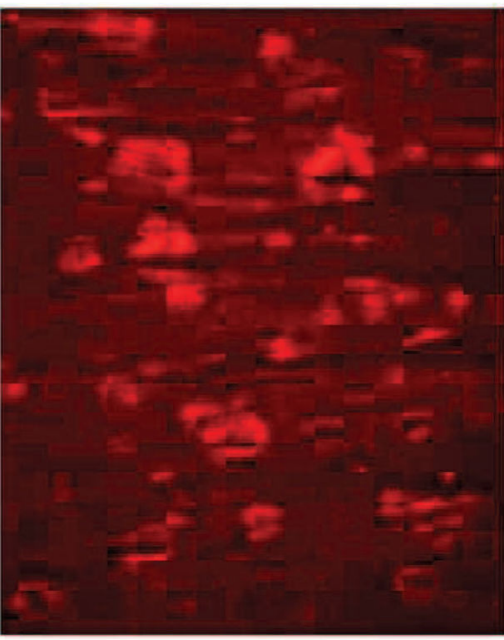

C

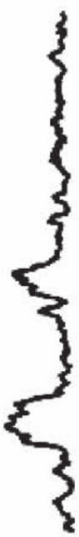

$\widehat{E} X_{1} Y(5 \mu m)$

| $400 \mathrm{AFU}$<smiles>[AlH2]</smiles>

GSK101 (3 nM)

WT

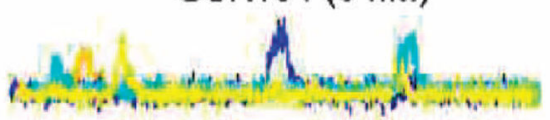

$+\operatorname{CCh}(10 \mu \mathrm{M})$

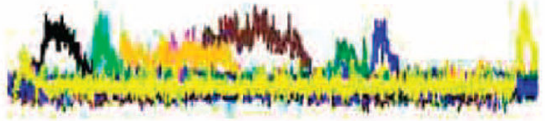

AKAP $150^{-1-}$

GSK101 (3 nM)
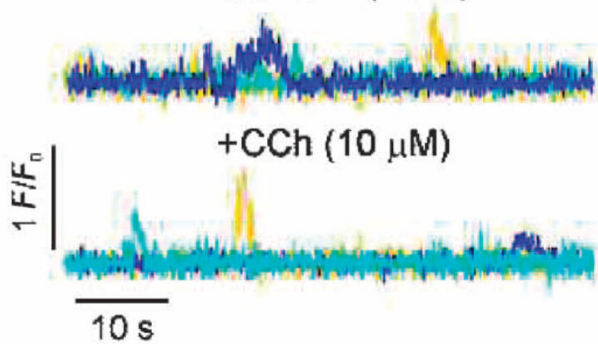

Merge

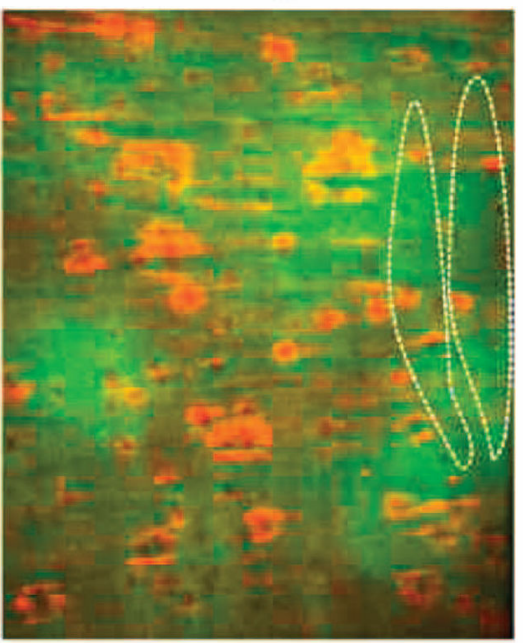

D

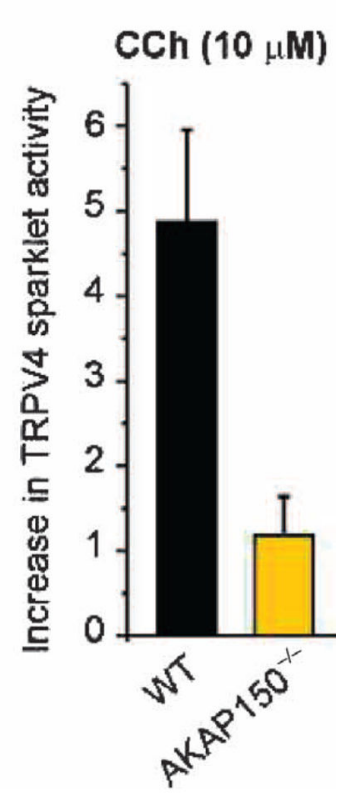

Fig. 2. MEP-localized AKAP150 is required for $\mathrm{CCh}$-induced activation of TRPV4 sparklets (A) Images of an en face mesenteric artery preparation from a C57BL6 mouse showing AKAP150 immunostaining (center, red) at the level of the inner elastic lamina (IEL) (left, green); $93.1 \pm 0.8 \%$ of holes in the IEL exhibited AKAP150 immunostaining ( $n=10$ fields, five arteries). Dotted lines in the merged image indicate the outlines of two ECs. (B) Threedimensional view along the $z$ axis ( $3 \mu \mathrm{m}, 0.1-\mu \mathrm{m}$ optical slices) showing densities of AKAP150 fluorescence projecting through the depth of the IEL. Reconstructed $x z$ and $y z$ images show AKAP150 immunostaining along the MEP, with strongest staining toward the end of the projections. Traces are plot profiles for AKAP150 staining along $x$ and $y$ axes for 
5- $\mu \mathrm{m}$-wide transects through the projections shown in the three-dimensional view. (C) Representative $F / F_{0}$ traces of TRPV $4 \mathrm{Ca}^{2+}$ sparklets in mesenteric arteries from wild-type (WT) mice (top) and AKAP150-/- mice (bottom). The experiments were performed in Fluo-4-loaded mesenteric arteries from WT and AKAP150-/- mice in the presence of CPA $(30 \mu \mathrm{M})$ and GSK101. Each color represents a trace from an individual region of interest (ROI). (D) Bar plots illustrating the CCh-induced increase in sparklet activity in the ECs of mesenteric arteries from WT and AKAP150-I- mice in the presence of GSK101. Data are means $\pm \operatorname{SEM}(n=5$ to 6 fields, four to five arteries; $P<0.01, t$ test). Information on the number and size of holes, and the depth of the IEL is provided in table S4. 
A

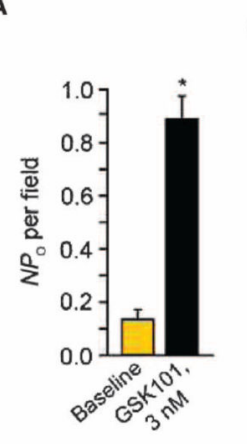

B

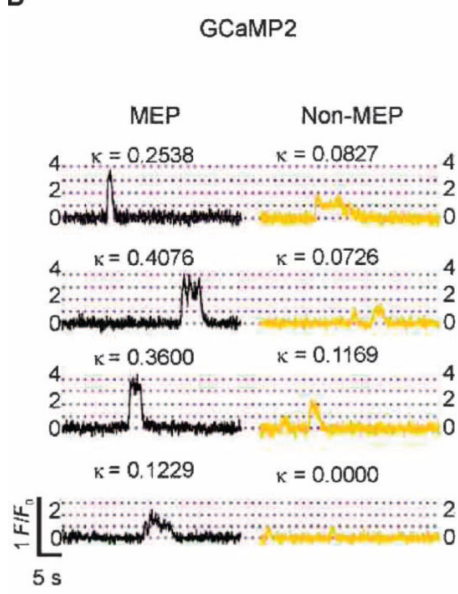

C

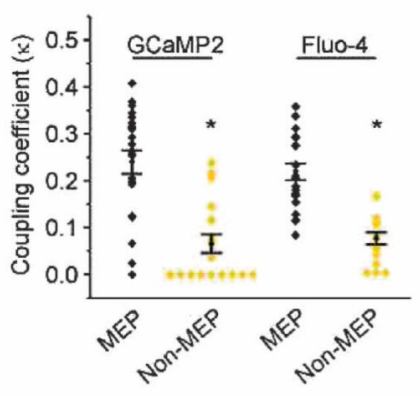

D

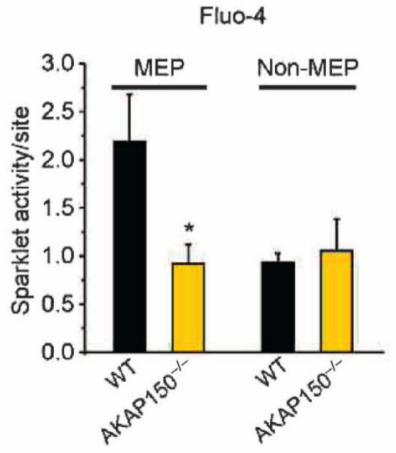

E

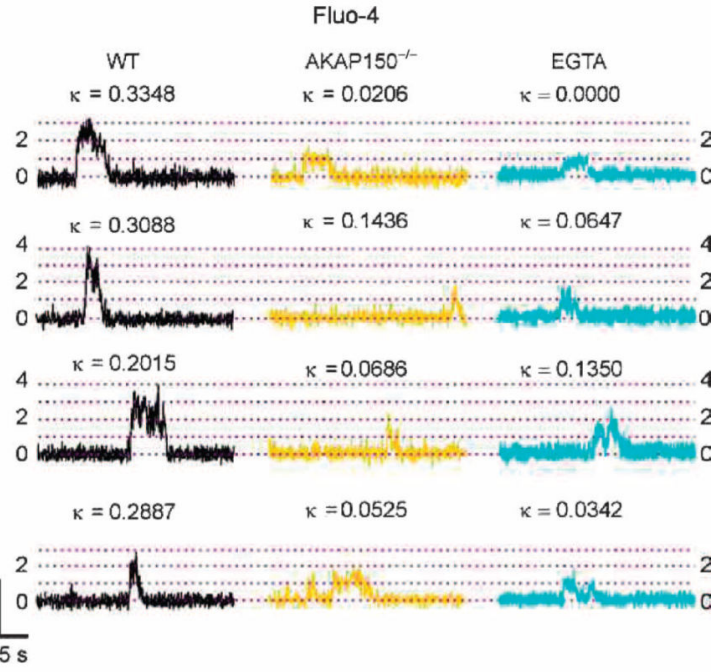

F

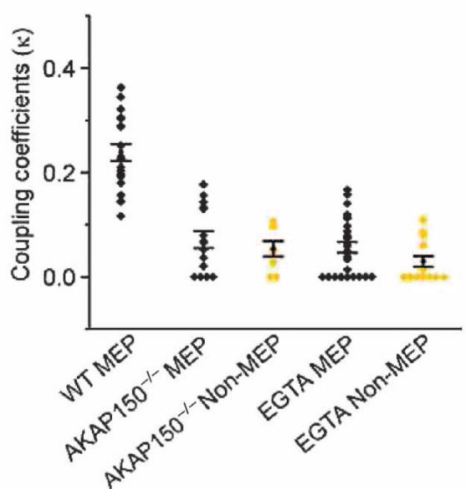

Fig. 3. AKAP150 and local $\mathrm{Ca}^{2+}$ are responsible for coupled gating of TRPV4 channels at MEPs TRPV4 $\mathrm{Ca}^{2+}$ sparklets were recorded in mesenteric arteries from GCaMP2 mice or Fluo-4loaded mesen-teric arteries in en face preparations in the presence of CPA $(30 \mu \mathrm{M})$ and GSK101 (3 nM). (A) Left: Effect of GSK101 on the average number of active TRPV4 channels $\left(N P_{\mathrm{O}}\right)$ per field ( $n=7$ fields, 5 arteries). Right: Sparklet activity per site $(* P<$ $0.05, t$ test; $n=21$ to 38 sites) and the percentage of sparklet sites per field at MEP and nonMEP sites ( ${ }^{*} P<0.05, t$ test; $n=7$ fields). (B) Representative $F / F_{0}$ traces from four different TRPV4 $\mathrm{Ca}^{2+}$ sparklet sites at MEP and non-MEP locations on the EC membrane [quantal 
level: $\left.0.19 \Delta F / F_{0}(1)\right]$. Respective coupling coefficient $(\kappa)$ values are shown above each trace. (C) Scatter plot indicating individual $\kappa$ values for sparklet sites at MEP and non-MEP locations. The mean coupling coefficient and SEM for each group are indicated $(P<0.01, t$ test). (D) Sparklet activity per site at MEP and non-MEP locations in mesenteric arteries from WT and AKAP $150^{-/-}$mice ( ${ }^{*} P<0.05, t$ test; 14 to 25 sites). (E) Representative $F / F_{0}$ traces from four different TRPV4 $\mathrm{Ca}^{2+}$ sparklet sites at MEPs from WT mice in the absence (left, black) or presence (right, cyan) of EGTA-AM $\left(10 \mu \mathrm{M}\right.$ for $10 \mathrm{~min}$ at $\left.36^{\circ} \mathrm{C}\right)$ or AKAP $150^{-/-}$(middle, yellow) mice. Respective $\kappa$ values are shown above each $F / F_{0}$ record [quantal level: $0.29 \Delta F / F_{0}(1)$ ]. (F) Scatter plot showing individual $\kappa$ values for sparklet sites at MEPs from the groups in (E). The plot also shows the mean coupling coefficient and SEM for each group ( $n=8$ to 27 sites). A one-way ANOVA with post hoc Bonferroni test was used to estimate $P$ values. $P<0.05$ for WT MEP versus all other groups, and for WT non-MEP versus EGTA non-MEP. 

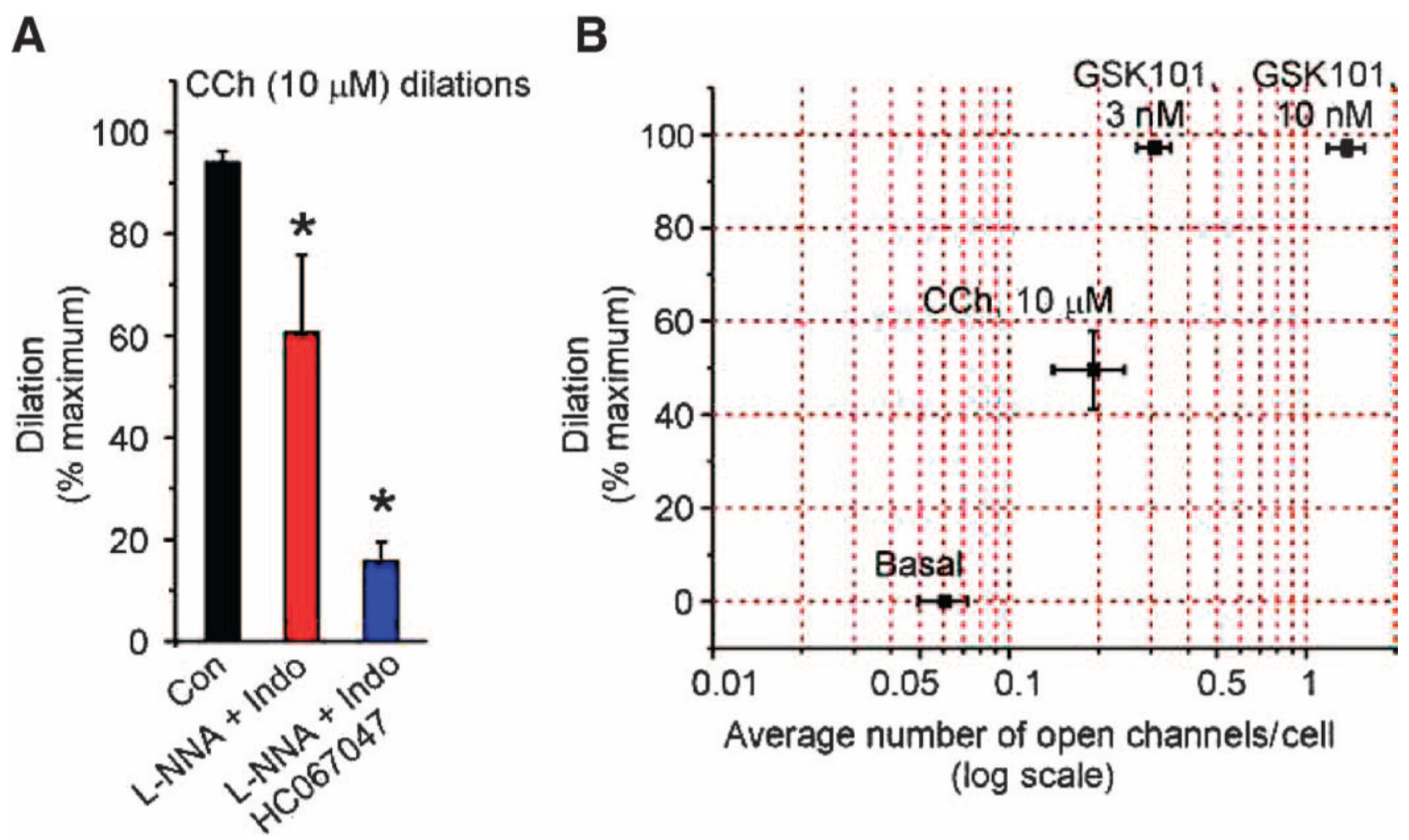

Fig. 4. Activation of less than one TRPV4 channel per EC causes maximum dilation of mesenteric arteries

(A) Bar graph showing dilatory responses to $\mathrm{CCh}$ alone (Con) and in the presence of the NOS and COX inhibitors L-NNA $(100 \mu \mathrm{M})$ and indomethacin (Indo; $10 \mu \mathrm{M})$, respectively, to isolate the EDH component of the dilation, or in the presence of ${ }_{\mathrm{L}} \mathrm{NNA}$, Indo, and HC-067047 (1 $\mu \mathrm{M}$; TRPV4 inhibitor), to identify the EDH-mediated dilation that is dependent on TRPV4. Maximal dilation was defined as that in the presence of $\mathrm{Ca}^{2+}$-free PSS. Data are means \pm SEM ( $n=5$ to 7 arteries); $* P<0.05$ using one-way ANOVA with post hoc Bonferroni test. (B) HC-067047-sensitive (TRPV4) component of dilation in response to $\mathrm{CCh}$, and GSK101 was plotted as a function of average TRPV4 channel activity per EC. The average number of TRPV4 channels activated per EC throughout the recording duration of 2 min was estimated by dividing the fluorescence integrals from all sparklet sites in an EC by the fluorescence integral of one quantal level (one channel) for $2 \mathrm{~min}$. Data are means \pm SEM ( $n=5$ to 7 arteries for dilation; 14 to 26 cells for average number of channels per cell). 
A
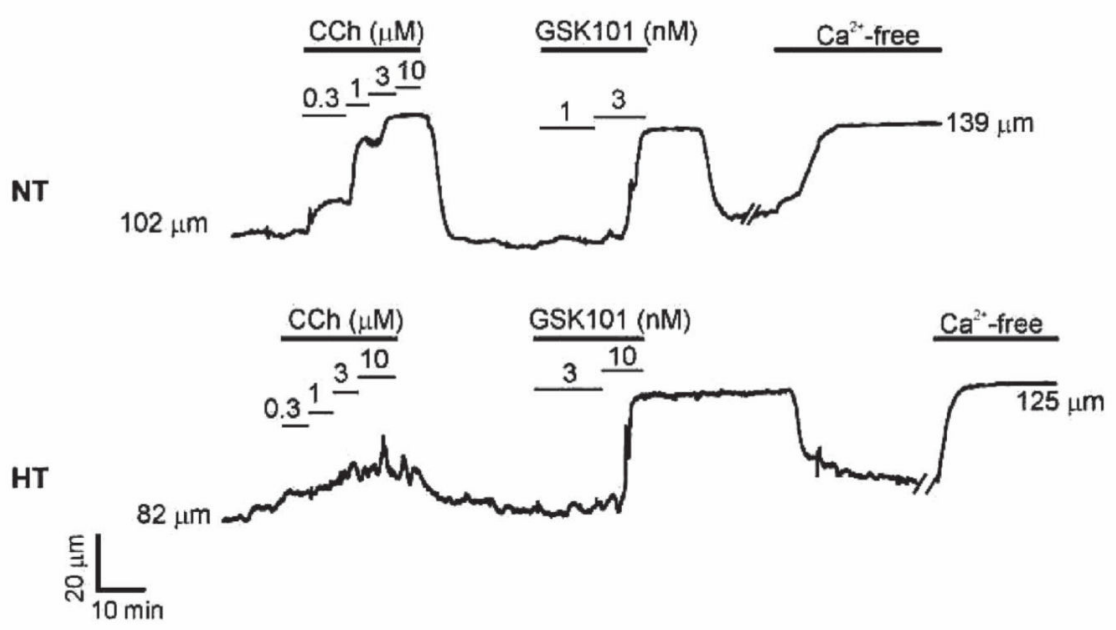

B

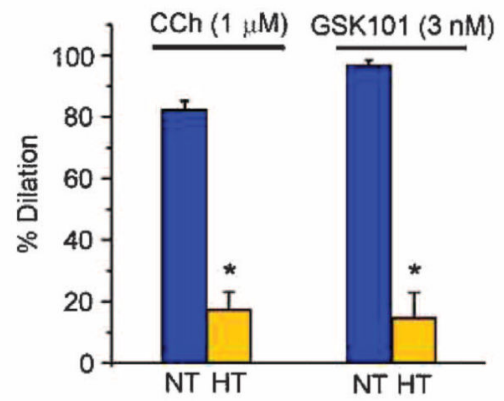

D

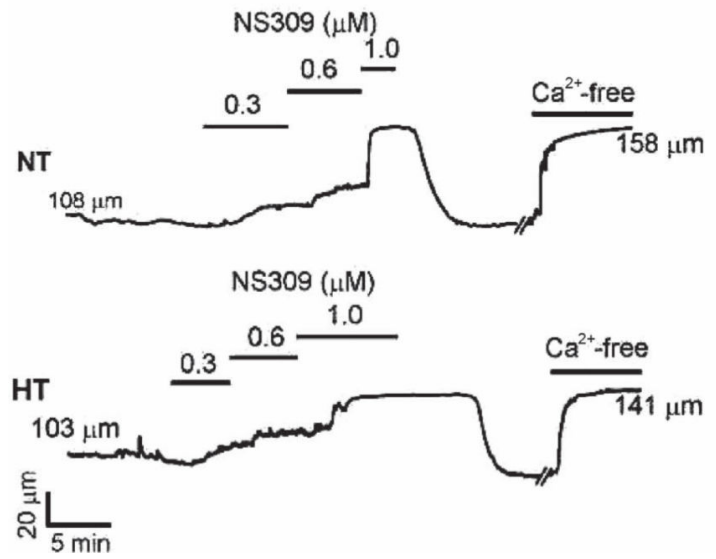

C

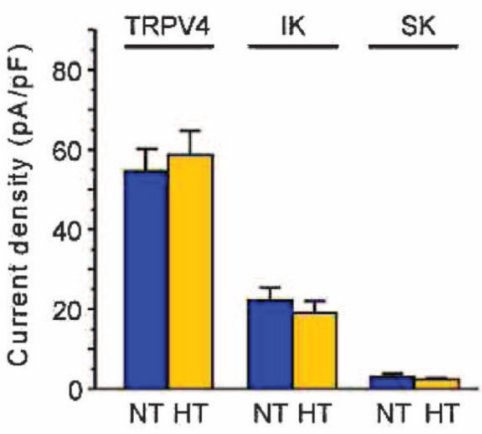

$E$

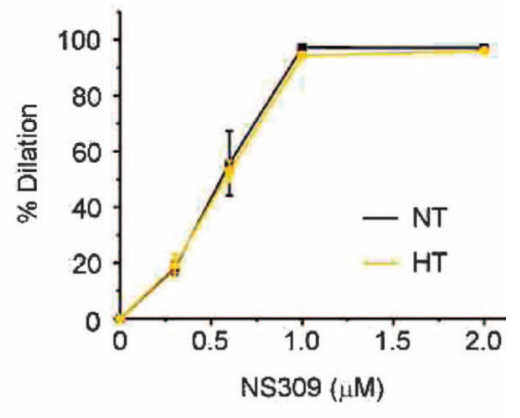

Fig. 5. EDH-mediated dilation is absent in arteries from hypertensive mice, but the function of individual ion channels is unaltered

Dilation studies in pressurized $(80 \mathrm{mmHg})$ third-order mesenteric arteries from normotensive (NT) and hypertensive (HT) mice. (A) Representative vessel internal diameter traces in response to CCh or GSK101. (B) Summary of diameter data comparing the responses of NT and HT mouse arteries to CCh and GSK101 ( $n=5$ to 6 arteries from five NT and HT mice; $* P<0.01, t$ test). Data are means \pm SEM. The maximum vessel dilation was determined from the diameter obtained in $\mathrm{Ca}^{2+}$-free solution. (C) Summary data 
showing maximum current densities of TRPV4 (at $+100 \mathrm{mV}$ ), IK, and SK channels (both at $0 \mathrm{mV}$ ) in ECs from NT and HT mice ( $n=5$ to 8 cells). (D and E) Representative diameter traces (D) and summary of diameter data (E) showing dilation in response to the IK and SK channel opener NS309 (0.3 to $2 \mu \mathrm{M})$ in mesenteric arteries from NT and HT mice. Data are means $\pm \operatorname{SEM}$ ( $n=5$ to 12 arteries). The averaged values for internal diameters are provided in tables $\mathrm{S} 2$ to $\mathrm{S} 4$. 
A

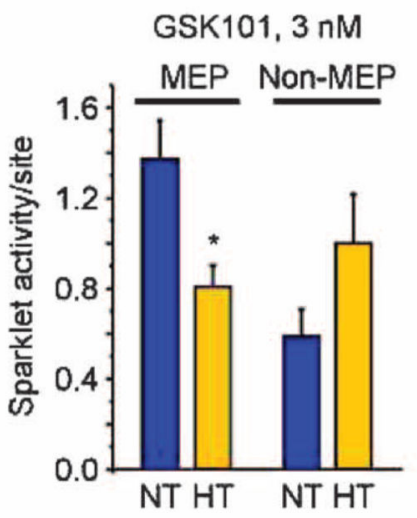

D

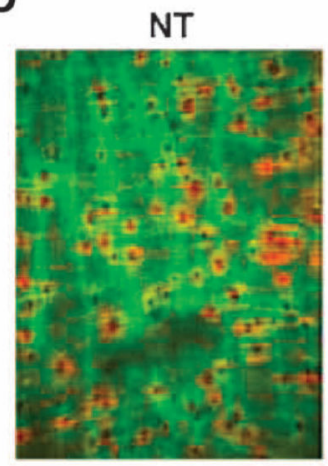

B

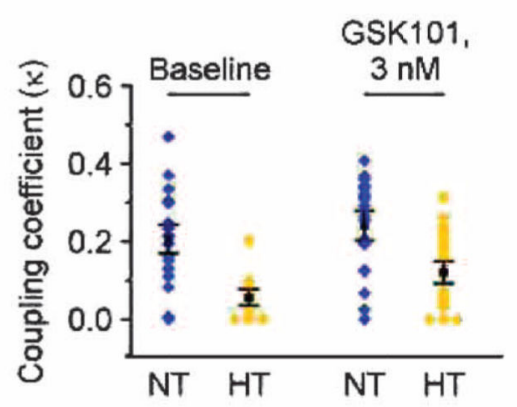

$\mathbf{E}$

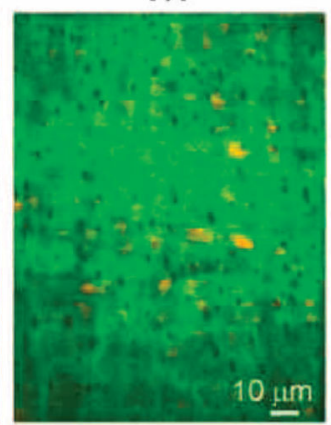

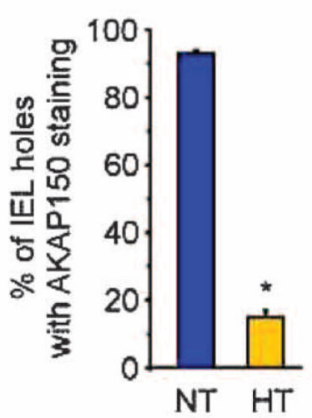

C

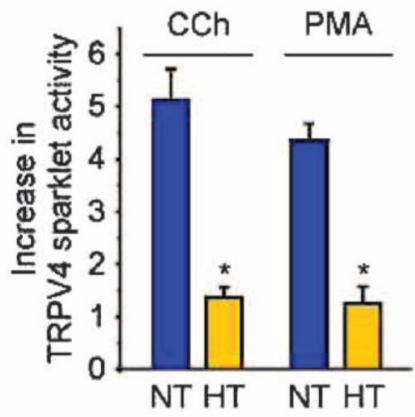

$\mathbf{F}$

NT
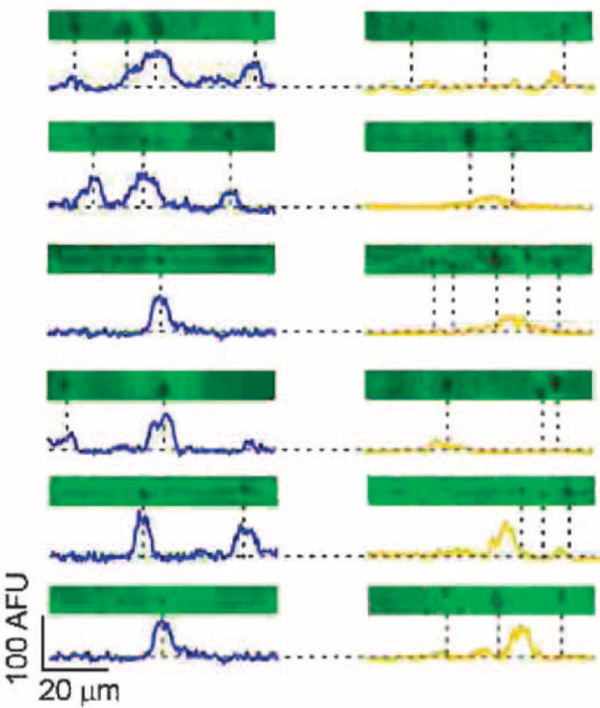

Fig. 6. Loss of MEP localization of AKAP150 in hypertensive mice leads to defective local $\mathrm{Ca}^{2+}$ signaling at MEPs and the loss of EDH-mediated dilation

(A) Sparklet activity per site for MEP and non-MEP sites in mesenteric arteries from NT and HT mice in the presence of GSK101 (10 to 13 arteries, $n=21$ to 46 sites; ${ }^{*} P<0.05, t$ test). (B) Scatter plots summarizing coupling coefficient ( $\kappa)$ data for TRPV4 sparklets at MEPs in NT and HT mice $(P<0.01$ for comparisons at baseline and in the presence of GSK101, $t$ test). (C) Summary data illustrating the loss of activation of TRPV4 sparklets by CCh and PMA in HT arteries in the presence of GSK101 ( $3 \mathrm{nM} ; n=4$ to 5 arteries; ${ }^{*} P<$ $0.01, t$ test). (D) Representative images of AKAP150 staining in en face preparations of mesenteric arteries from NT and HT mice. (E) Summary data of AKAP150-immunostaining data shown in (D). The number of holes with identifiable AKAP150 staining is expressed as a percentage of the total number of holes in the internal elastic lamina per field $(n=5$ arteries; $* P<0.01, t$ test). (F) Plot profiles of AKAP150 immunostaining for representative horizontal transects ( $5 \mu \mathrm{m}$ wide by $70 \mu \mathrm{m}$ long) through the images in (D) encompassing holes. Dotted lines indicate the position of MEPs, located at holes in the IEL. Information on 
the number and sizes of holes, and the depth of the IEL in NT and HT mice is provided in table S4. 


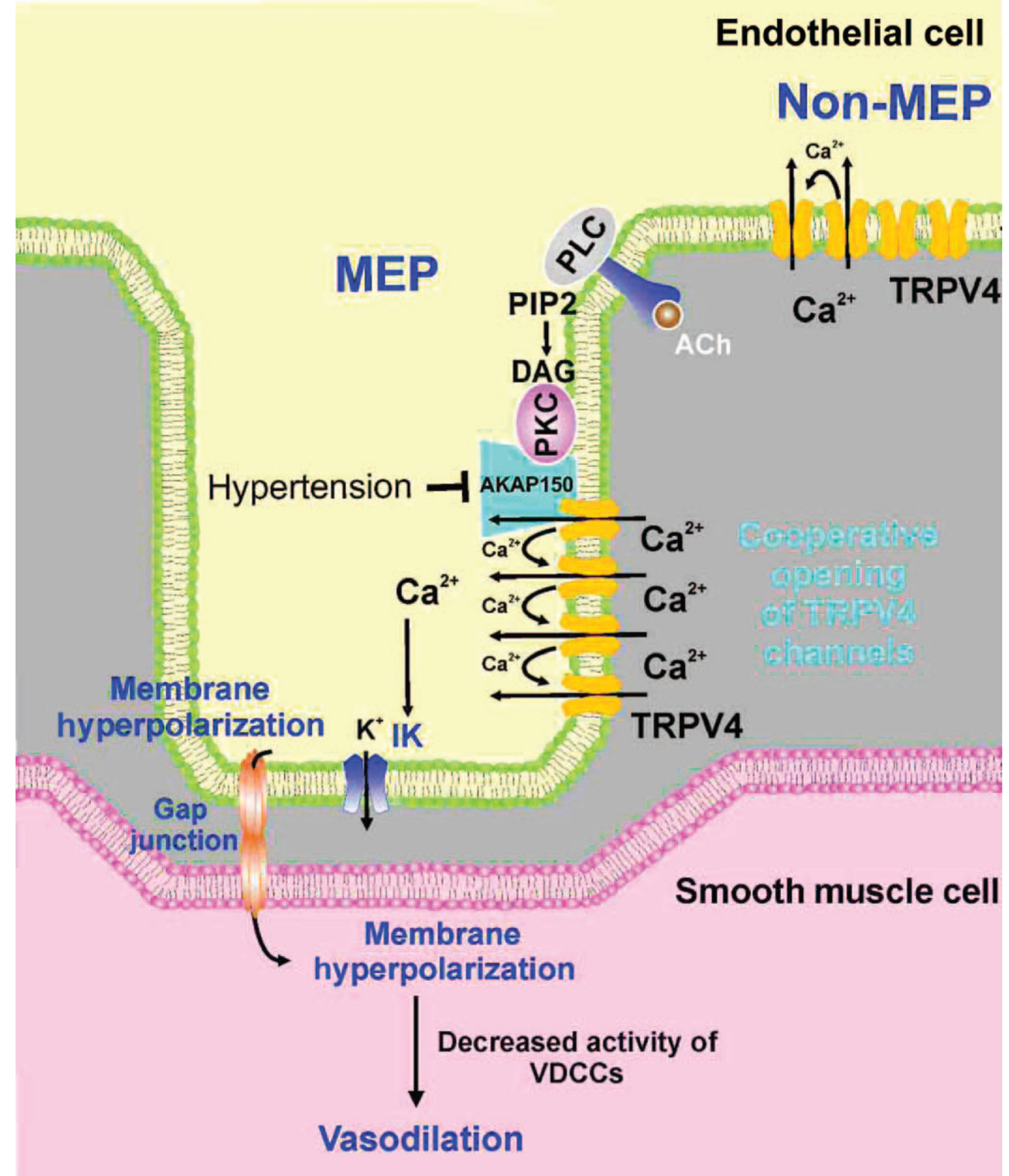

Fig. 7. Proposed scheme for the organization and function of TRPV4 channels at MEPs TRPV4 channels on the EC membrane exist in clusters of four channels at both MEP and non-MEP sites. Cooperative opening of TRPV4 channels depends on intracellular $\mathrm{Ca}^{2+}$ and AKAP150, which is concentrated at MEPs. Muscarinic receptor activation of TRPV4 channels occurs only at MEPs through AKAP150-anchored PKC. $\mathrm{Ca}^{2+}$ influx through activated TRPV4 channels activates IK channels and hyperpolarizes ECs, leading to hyperpolarization of SMC through gap junctions. Hyper-polarization reduces the activity of VDCCs in the SMCs, causing vaso-dilation. Endothelial dysfunction in Ang II-induced 
hypertension involves a loss of AKAP150 at MEPs, which uncouples muscarinic receptor signals to TRPV4 channels and disrupts cooperativity among TRPV4 channels. Although the current consensus is that EDH primarily involves electronic spread to the SMCs through gap junctions, soluble endothelium-derived hyperpolarizing factors (EDHFs, not shown) are released as a result of IK and SK channel activation may also contribute in certain circumstances. 
Table 1

Changes in TRPV4 sparklet sites per field and average number of open TRPV4 channels $\left(N P_{O}\right)$ per site

CPA $(30 \mu \mathrm{M})$ was included under all conditions. The PLC inhibitor U73122 $(5 \mu \mathrm{M})$ was added 10 min before the addition of CCh. The PKC inhibitor Gö-6976 $(1 \mu \mathrm{M})$ was added $10 \mathrm{~min}$ before CCh $(10 \mu \mathrm{M})$, OAG $(10$ $\mu \mathrm{M})$, or PMA $(10 \mathrm{nM})$. The TRPV4 inhibitor HC-067047 $(1 \mu \mathrm{M})$ was added after CCh, OAG, or PMA for 10 min. The data in the presence of GSK101 (3 nM) represent sparklet sites at MEPs. Significant differences were assessed by paired $t$ test or one-way ANOVA with post hoc Bonferroni test. $* P<0.05$; ns, not significant (versus basal or GSK101, unless specified).

\begin{tabular}{|c|c|c|c|c|}
\hline Stimulation conditions & Active sites per field & $N P_{O}$ per site & $n$ & Significant difference \\
\hline Basal & $2.2 \pm 0.4$ & $0.05 \pm 0.02$ & 10 & \\
\hline$+\mathrm{CCh}$ & $5.0 \pm 0.8$ & $0.15 \pm 0.02$ & 10 & $*$ \\
\hline$+\mathrm{CCh}+\mathrm{HC}-067047$ & $2.0 \pm 0.4$ & $0.03 \pm 0.01$ & 5 & $*$ (versus CCh) \\
\hline Basal + U73122 & $2.2 \pm 0.2$ & $0.04 \pm 0.02$ & 5 & \\
\hline$+\mathrm{CCh}$ & $2.4 \pm 0.3$ & $0.06 \pm 0.02$ & 5 & ns \\
\hline Basal & $3.1 \pm 0.4$ & $0.04 \pm 0.01$ & 8 & \\
\hline$+\mathrm{OAG}$ & $4.8 \pm 0.2$ & $0.12 \pm 0.02$ & 8 & $*$ \\
\hline + OAG + HC-067047 & $1.6 \pm 0.4$ & $0.05 \pm 0.01$ & 5 & * (versus OAG) \\
\hline Basal & $2.6 \pm 0.4$ & $0.05 \pm 0.01$ & 8 & \\
\hline+ PMA & $4.9 \pm 0.8$ & $0.13 \pm 0.02$ & 8 & $*$ \\
\hline + PMA + HC-067047 & $1.8 \pm 0.4$ & $0.04 \pm 0.01$ & 4 & * (versus PMA) \\
\hline Basal + Gö-6976 & $2.2 \pm 0.4$ & $0.06 \pm 0.02$ & 9 & \\
\hline Gö-6976 + CCh & $2.8 \pm 0.3$ & $0.04 \pm 0.01$ & 9 & ns \\
\hline Basal + Gö-6976 & $3.4 \pm 0.6$ & $0.06 \pm 0.02$ & 9 & \\
\hline Gö-6976 + OAG & $3.1 \pm 0.6$ & $0.05 \pm 0.02$ & 9 & ns \\
\hline Basal + Gö-6976 & $2.5 \pm 0.2$ & $0.05 \pm 0.01$ & 9 & \\
\hline Gö-6976 + PMA & $3.6 \pm 0.6$ & $0.03 \pm 0.01$ & 9 & ns \\
\hline GSK101, MEPs & $6.4 \pm 0.7$ & $0.07 \pm 0.02$ & 7 & \\
\hline$+\mathrm{CCh}$ & $14.8 \pm 1.4$ & $0.16 \pm 0.03$ & 7 & $*$ \\
\hline$+\mathrm{CCh}+\mathrm{HC}-067047$ & $2.0 \pm 0.6$ & $0.08 \pm 0.02$ & 4 & $*$ (versus CCh) \\
\hline GSK101, MEPs & $7.1 \pm 1.0$ & $0.09 \pm 0.02$ & 4 & \\
\hline$+\mathrm{OAG}$ & $17.1 \pm 1.6$ & $0.17 \pm 0.03$ & 4 & $*$ \\
\hline + OAG + HC-067047 & $4.0 \pm 0.8$ & $0.05 \pm 0.01$ & 3 & * (versus OAG) \\
\hline GSK101, MEPs & $6.3 \pm 1.2$ & $0.08 \pm 0.01$ & 5 & \\
\hline+ PMA & $12.0 \pm 2.4$ & $0.19 \pm 0.02$ & 5 & $*$ \\
\hline + PMA + HC-067047 & $3.3 \pm 0.3$ & $0.04 \pm 0.01$ & 3 & * (versus PMA) \\
\hline \multicolumn{5}{|l|}{ MEPs } \\
\hline GSK101 + Gö-6976 & $6.8 \pm 1.3$ & $0.07 \pm 0.02$ & 7 & \\
\hline$+\mathrm{CCh}$ & $6.9 \pm 1.0$ & $0.07 \pm 0.03$ & 7 & ns \\
\hline GSK101 + Gö-6976 & $7.4 \pm 1.6$ & $0.08 \pm 0.03$ & 4 & \\
\hline$+\mathrm{OAG}$ & $8.1 \pm 1.9$ & $0.08 \pm 0.02$ & 4 & ns \\
\hline GSK101 + Gö-6976 & $6.5 \pm 1.2$ & $0.06 \pm 0.02$ & 3 & \\
\hline
\end{tabular}




\begin{tabular}{lcccc}
\hline Stimulation conditions & Active sites per field & $\boldsymbol{N P}_{\mathbf{O}}$ per site & $\boldsymbol{n}$ & Significant difference \\
\hline + PMA & $7.6 \pm 1.6$ & $0.07 \pm 0.01$ & 3 & $\mathrm{~ns}$ \\
\hline
\end{tabular}

